\title{
Cal Poly's AMELIA 10 Foot Span Hybrid Wing-Body Low Noise CESTOL Aircraft Wing Tunnel Test and Experimental Results Overview
}

\author{
Kristina K. Jameson ${ }^{1}$, David D. Marshall ${ }^{2}$, Robert Ehrmann ${ }^{3}$, Jonathon A. Lichtwardt ${ }^{4}$ \\ and Eric N. Paciano 5 \\ California Polytechnic State University, San Luis Obispo, CA, 93407 \\ Robert J. Englar ${ }^{6}$ \\ Georgia Tech Research Institute, Atlanta, GA 30332-0844 \\ and \\ William C. Horne ${ }^{7}$ \\ NASA Ames Research Center, Mountain View, Ca 94043
}

\begin{abstract}
A collaboration between California Polytechnic Corporation with Georgia Tech Research Institute (GTRI) and DHC Engineering worked on a NASA NRA to develop predictive capabilities for the design and performance of Cruise Efficient, Short Take-Off and Landing (CESTOL) subsonic aircraft. The work presented in this paper gives details of a large scale wind tunnel effort to validate predictive capabilities for this NRA for aerodynamic and acoustic performance during takeoff and landing. The model, Advanced Model for Extreme Lift and Improved Aeroacoustics (AMELIA), was designed as a 100 passenger, $N+2$ generation, regional, cruise efficient short takeoff and land (CESTOL) airliner with hybrid blended wing-body with circulation control. AMELIA is a 1/11 scale with a corresponding $10 \mathrm{ft}$ wing span. The National Full-Scale Aerodynamic Complex (NFAC) $40 \mathrm{ft}$ by $80 \mathrm{ft}$ wind tunnel was chosen to perform the large-scale wind tunnel test. The NFAC was chosen because both aerodynamic and acoustic measurements will be obtained simultaneously, the tunnel is large enough that the
\end{abstract}

\footnotetext{
${ }^{1}$ Assistant Professor, Aerospace Engineering, San Luis Obispo, Ca 93407, AIAA Member.

${ }^{2}$ Associate Professor, Aerospace Engineering, San Luis Obispo, Ca 93407, AIAA Member.

${ }^{3}$ Graduate Student, Aerospace Engineering, San Luis Obispo, Ca 93407, AIAA Student Member.

${ }^{4}$ Graduate Student, Aerospace Engineering, San Luis Obispo, Ca 93407, AIAA Student Member.

${ }^{5}$ Graduate Student, Aerospace Engineering, San Luis Obispo, Ca 93407, AIAA Student Member.

${ }^{6}$ Principal Research Engineer, Georgia Tech Research Institute, Atlanta, GA 30332, AIAA Member.

${ }^{7}$ Senior Research Engineer, Mountain View 94043, AIAA Member.
} 
downwash created by the powered lift did not impinge on the tunnel walls, and the schedule and cost fit into Cal Poly's time frame and budget. Several experimental measurement techniques were used to obtain the necessary data to validate predictive codes being developed as apart of this effort: along with the traditional forces and moments measurements, stationary microphones were used to obtain far-field acoustic measurements including a 48 element phased array, the Fringe-Image Skin Friction (FISF) technique was used to measure the global skin friction on the wing, surface mounted steady and unsteady pressure transducers were used to obtain local pressure distributions over the model, and oil and smoke flow visualization techniques were employed to understand the effects of the powered lift system in AMELIA. The paper gives a brief summary of AMELIA's performance for variable tunnel speed, momentum mass flow, engine simulator height, and angle of attack.

\section{Introduction}

$\mathrm{W}$ ith the recent advent of NASA's Environmentally Responsible Aviation Project (ERA) ${ }^{1}$, which is dedicated to designing aircraft that will reduce the impact of aviation on the environment, there is a need for research and development of methodologies to minimize fuel burn, emissions, and reduce community noise produced by regional airlines. ERA tackles airframe technology, propulsion technology, and vehicle systems integration to meet performance objectives in the time frame for the aircraft to be at a Technology Readiness Level (TRL) of 4- 6 by the year of 2020 (deemed $N+2$ ). The proceeding project that investigated similar goals to ERA was NASA's Subsonic Fixed Wing (SFW). SFW focused on conducting research to improve prediction methods and technologies that will produce lower noise, lower emissions, and higher performing subsonic aircraft for the Next Generation Air Transportation System.

The work provided in this summary paper was a NASA Research Announcement (NRA) contract funded by Subsonic Fixed Wing. The project started in 2007 with a specific goal of conducting a large-scale wind tunnel test along with the development of new and improved predictive codes for the advanced powered-lift concepts. Many of the predictive codes were incorporated to refine the wind tunnel model outer mold line design. The large scale wind tunnel test goal was to investigate powered lift technologies and provide an experimental database to validate current and future modeling techniques. Powered-lift concepts investigated were Circulation Control (CC) wing in conjunction with over-the-wing mounted engines to entrain the exhaust to further increase the lift generated by $\mathrm{CC}$ technologies alone. The NRA was a five-year effort; during the first year the objective was to select and refine CESTOL concepts and then to complete a preliminary design of a large-scale wind tunnel model for the large scale test. During the second, third, and fourth years the large-scale wind tunnel model design would be completed, manufactured, and calibrated. During the fifth year the large scale wind tunnel test was conducted.

This summary paper will describe the AMELIA wind tunnel portion of the project, highlighting the internal configuration of AMELIA and the internal/external measurements 
chosen in order to satisfy the requirements of obtaining a database of experimental data to be used for future computational model validations. A summary of the supporting modeling efforts involved in the NRA can be found in Ref. 2. The conceptual designs considered for this project and the decision process that lead to the selected configuration adapted for the AMELIA wind tunnel model are discussed in Ref. 3. The external experimental techniques that were employed during the test, along with the large-scale wind tunnel test facility are covered in great detail. Experimental measurements in the database include forces and moments, and surface pressure distributions, local skin friction measurements, boundary and shear layer velocity profiles, farfield acoustic data and noise signatures from turbofan propulsion simulators. Results and discussion of the circulation control performance, over the wing mounted engines, and the combined performance is also briefly discussed, a more in-depth discussion of the wind tunnel test results can be found in Ref. 4.

The wind tunnel test was conducted at the National Full Scale Aerodynamic Complex (NFAC) starting in November of 2011 concluding in March of 2012. All wind tunnel test objectives were met or exceeded.

\section{Large Scale Wind Tunnel Model}

NASA is committed to identifying solutions that meet improvement goals for noise, emissions, and energy usage (fuel burn). They have classified the $\mathrm{N}+2$ design metrics as a $40 \%$ reduction in fuel consumption, progress towards $-42 \mathrm{~dB}$ lower noise levels, a $70 \%$ decrease in emissions, and a $50 \%$ reduction in field length performance over current generation aircrafts. Theoretically the

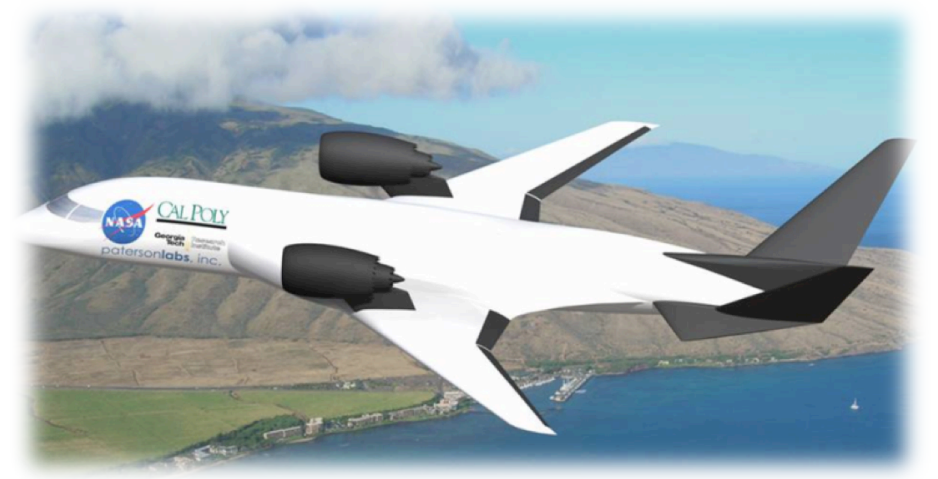

Figure 1. A conceptual design of AMELIA flying over Hawaii. aircraft should reach a Technology Readiness Level (TRL) of 4-6 by the year 2020. Dave Hall at DHC Engineering submitted conceptual design configurations to address the $\mathrm{N}+2$ goals. Cal Poly made the selection to one favorable configuration which became the model, Advanced Model for Extreme Lift and Improved Aeroacoustics (AMELIA). A conceptual representation of AMELIA can be seen in Fig. 1.

\section{A. AMELIA Manufacturing Considerations}

The primary wind tunnel test speed of $100 \mathrm{kts}$ was the main contributing factor to the material selection for the model. Both machined stainless steel and aluminum were chosen for their strength and ease of manufacturability, respectively. With the chosen material properties, the detailed structural integrity of the model was defined. Since the model design incorporated leading and trailing edge blowing slots, tolerance became one of the more important manufacturing considerations. After researching the smallest allowable tolerance for the slot geometry, it was found that the smallest slot could be at a height of $0.0115 \mathrm{in}$. This did not affect the existing trailing edge slot geometry, but increased the leading edge slot heights by $15 \%$ from the original designed slot. Another manufacturing consideration was the design and material of 
the low-pressure wing pressure plenums for the circulation control wings. The plenum design must allow adequate space for instrumentation while being small enough to have enough wall thickness to meet the appropriate safety factors.

\section{B. AMELIA Manufacturer}

Wind tunnel model fabrication posed the greatest technical risk, since the model directly affects the test data. Much research was devoted to finding credible manufacturers that would produce a model capable of meeting, and possibly exceeding, all of the testing priorities (explained in detail later in this paper). Along with finding the best-fit manufacturer, the model was adjusted to incorporate achievable tolerances and geometries. A total of eight different model manufacturers were contacted, requesting estimates on both a cost and schedule for the model design. The model manufacturer was eventually down selected to Patersonlabs Incorporated. They provided the most competitive cost and schedule, and were the most responsive during the proposal period. Patersonlabs also had prior experience building many complex models, including completing a model tested at NASA Ames Research Center's $11 \mathrm{ft}$ by $11 \mathrm{ft}$ Transonic Wind Tunnel. Patersonlabs once chosen, played a large role in the detailed and internal design of AMELIA. Specifically, Pateronlabs played the most vital role in the design of the internal low and high pressure air systems which are described in detail in the following sections.

\section{AMELIA Design Features}

In order to utilize the conceptual design shown in Fig. 1 in a large-scale wind tunnel test setting, many design modifications were needed. The most significant alteration to the geometry came in the mounting system of the wind tunnel model. A sting was chosen as the ideal method to measure aerodynamic forces and moments, mainly for its ability to take measurements nonintrusively. Direct mounting of the model to the sting through the aft end raised concerns with disturbing the flow around the beaver tail. An underbody mount was designed to provide an attachment location with minimal flow disturbance. The mount was faired with a clamshell blade that extends vertically from the sting tip. The blade mount also serves to extend the negative angle of attack limit. Figure 2 shows a three view drawing of the model mounted to the blade attachment with empennage removed and relevant dimensions shown. The tail empennage is not shown in the three-view because it was not attached to the model during testing in order to reduce the complexity of the tunnel model for computational modeling. The strakes and V-tail as seen in Fig. 1 were manufactured in order to supplement subsequent research and testing. These surfaces attach to the model via off blocks.

The selected configuration utilizes an optimized supercritical airfoil with a dual radius flap at the trailing edge. In order to minimize cost and complexity of the model, dual radius flaps of $0^{\circ}$, $30^{\circ}, 60^{\circ}$ and $90^{\circ}$ deflections were proposed, as opposed to a mechanical flap where the deflection angle can be varied. The $90^{\circ}$ flap deflection was later changed to $80^{\circ}$ due to issues with the manufacturing of the flap with the appropriate blowing slot height. The flaps utilized on AMELIA differed from that of the conceptual design, namely the inboard and out board flaps were modified to be a single continuous flap for each wing. This change was made in order to reduce the amount of flow disturbance from discontinuities of the flap surface as well as allowing for less complicated configuration changes while the model is mounted in the wind tunnel. A cut-away view of the model highlighting the internal and external design of AMELIA 
is shown in Fig. 3 as well as illustrating the model configuration with the $0^{\circ}$ and $80^{\circ}$ flap choices. Figure 3 also highlights many of AMELIA's unique features, such as the internal flow control systems, the balance block, and the support structure for the over the wing mounted engines.
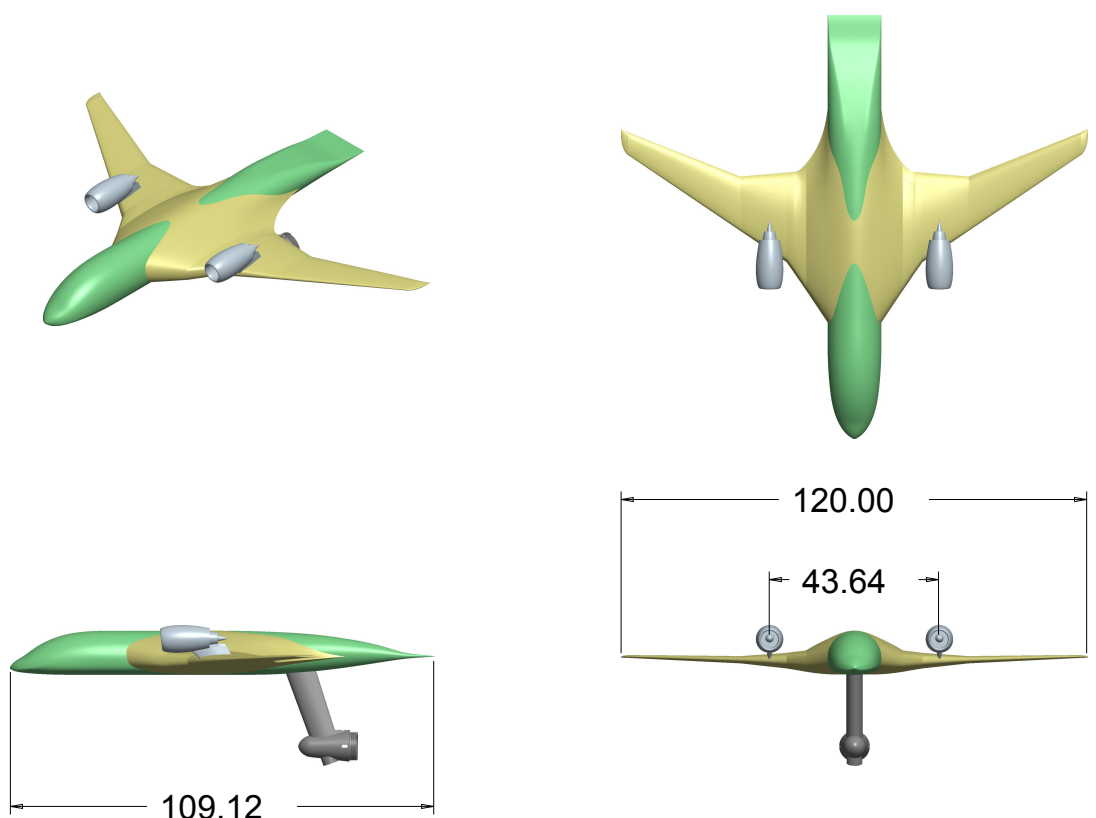

${ }^{*}$ Note: All Dimensions In Inches

Figure 2. A three-view drawing of AMELIA with sting-blade attachment and tail surfaces removed.

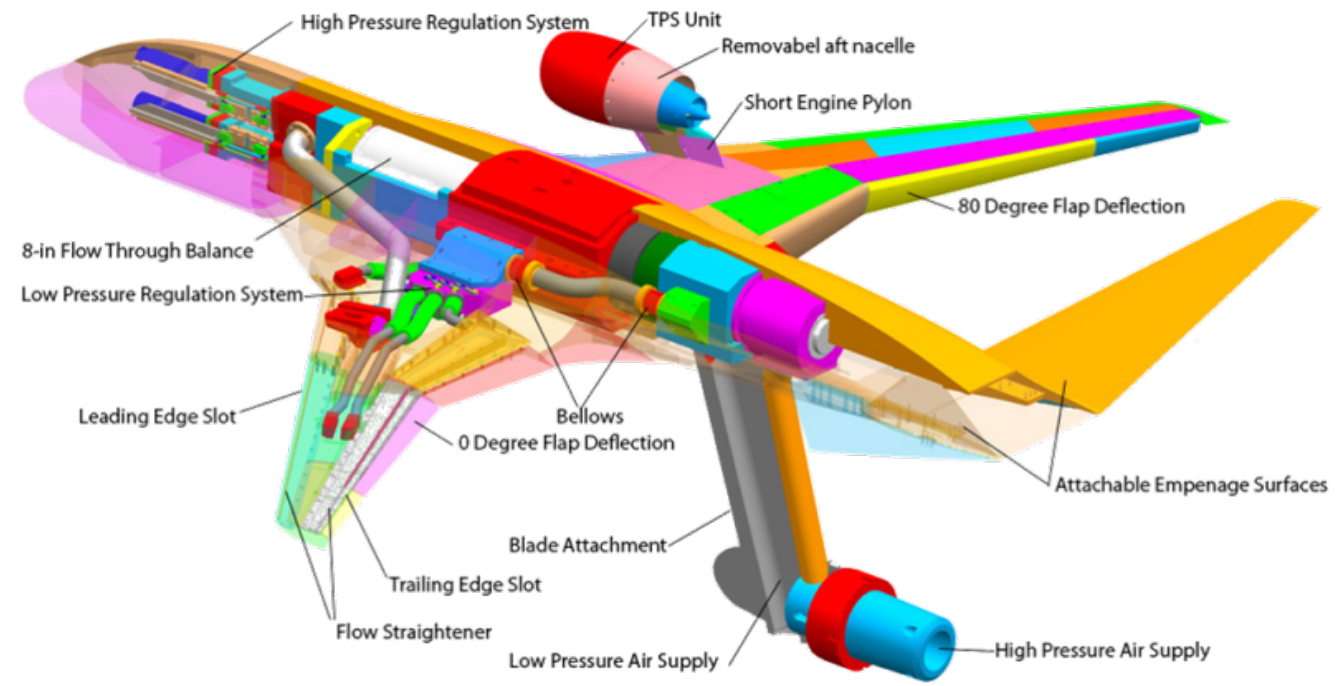

Figure 3. A section view of AMELIA, revealing the complex internal components highlighting the flow system for the powered lift system and the flow-though balance. 


\section{High and Low Pressure Air Systems}

Plumbing for preassureized-heated air enters the model though the sting-blade attachment supplying the necessary high and lower pressure air for the powered lift system. The larger blue fixture shown at the bottom of the schematic in Fig. 3 is the entry point for the high-pressure air required to power the Turbine Propulsion Simulator (TPS) units. This system (600 psi maximum determined by the limits of the flow through balance provided by the Triumph Group) first travels through the NFAC provided sting into the fabricated sting-blade attachment making two approximately 90o turns before entering the 8 " flow though balance. On the downstream side of the balance a separate flow control plenum and system regulates the air flow to the left and right TPS units. The airflow is adjusted using conical plugs that can be remotely controlled while the tunnel is in operation. The conical plugs are driven using MMP 24vdc gearmotors, and use linear potentiometers for position feedback. The plugs can be positioned to provide from 30-100\% mass flow. The TPS unit flow is supplied through stainless steel pipes that attach to wing mounted pylons. Figure 4a shows the complete rendering of the piping and mass flow control plenum for the high pressure air system along with the sting-blade attachment while $4 \mathrm{~b}$ is a head on view of the downstream flow control system highlighting the staggered plumping layout necessary to rout the pressurized line to each of the TPS units.
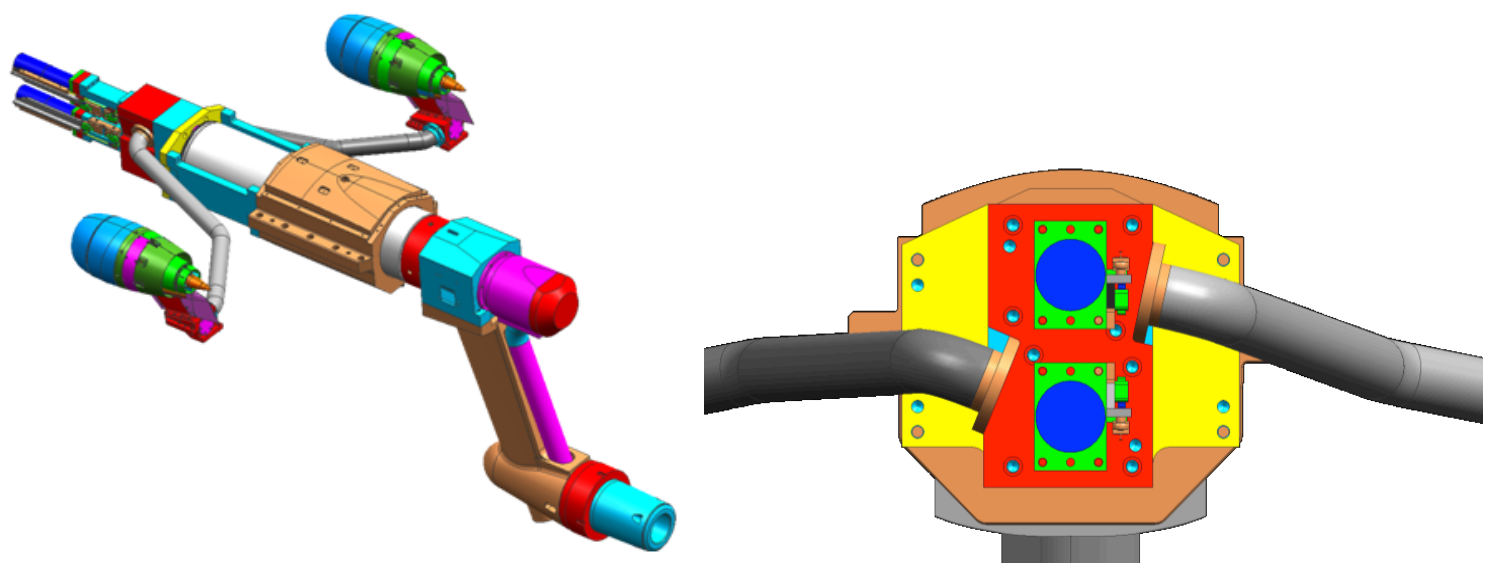

Figure 4. A schematic of the high pressure air system where (a) shows the complete system from model entry to the TPS units and (b) shows a head on view of the downstream mass flow control system.

The low pressure system (approximately $100 \mathrm{psi}$ ) will be used to supply the air to the plenums that feed the slots at the leading and trialing edges for the circulation control wing. This system is fed via a pipe attached to the underside of the sting arm, which connects to the blade body. Air travels up the blade where it is split into the left and right wings allowing for the conversion of non-metric to metric to be made though a two bellows system. Once the flow becomes metric on each wing the air is dispersed into low pressure plenum, shown purple in Fig. 5a and 5b. Each low pressure plenum consists of four butterfly valves controlled via $24 \mathrm{vdc}$ gear motors, with rotary pots for feedback allowing each of the slot plenums separate flow control from $0-100 \%$. The flow to each slot plenums will be remotely controlled allowing for quick response time during tunnel operation. 

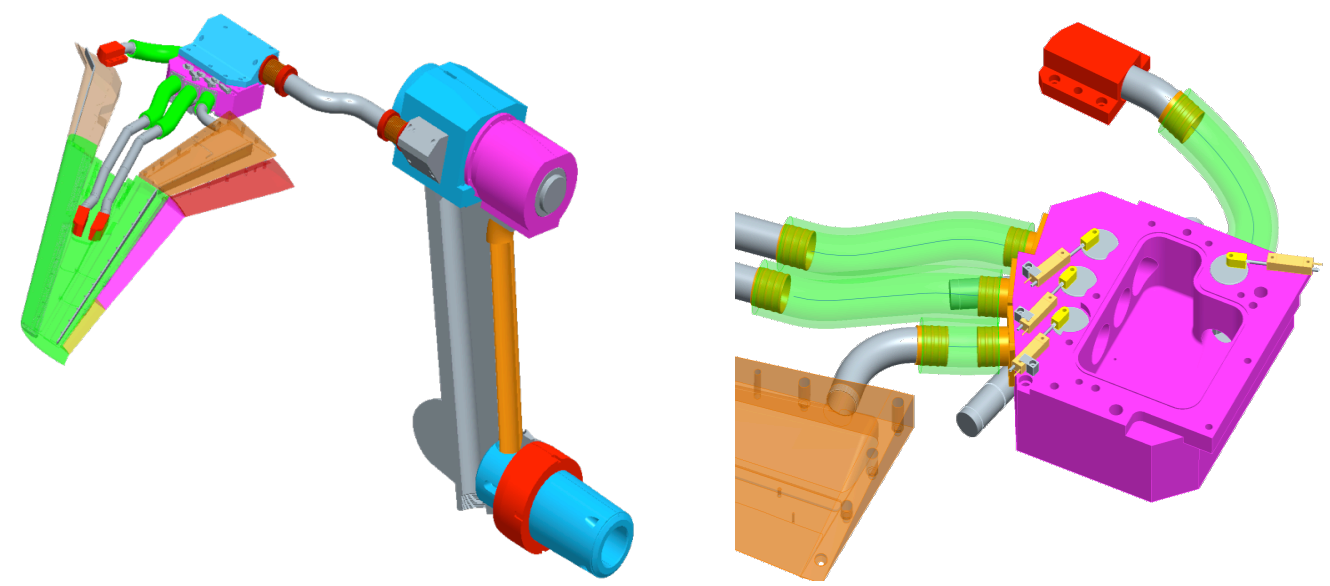

Figure 5. A schematic of the low pressure air system where (a) shows the complete system for the left wing including the plenums and plumping thought he sting blade attachment and (b) shows the structure for the internal mass flow control system for each of the four slot plenums in the left wing.

\section{E. Turbine Propulsion Simulators}

The turbine propulsion simulators were incorporated in the wind tunnel model as an attempt to replicate the exhaust flow of a turbofan engine. One of the primary research objects in this investigation is the ability to entrain engine exhaust from upper surface blowing with the flow from the circulation control wing. As a means to evaluate this entrainment ability, two separate

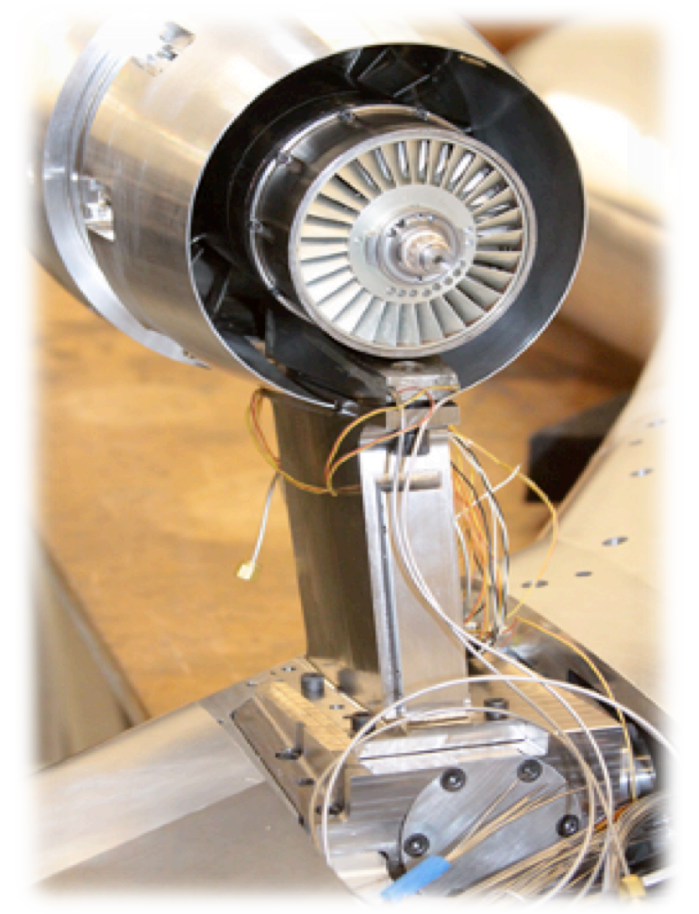

Figure 6. A photograph of the Model 441 TPS unit installed in the nacelle mounted on AMELIA. engine heights (approximately 4.25in for the low height and 6.25in for the high height from the wing surface to the outer nacelle) were investigated during testing. Height adjustments were completed using faired structural pylons. ${ }^{5,6}$ These pylons also act as pressure vessels within which the high pressure air is fed to the TPS units. Altering the model for engine height adjustments was projected to be the most time consuming modification and therefore the test matrix was designed around this assumption. The as-run test matrix started with the low engine height, moved the high engine height, and ended with the TPS and pylons removed completely to allow for the investigation of the circulation control wing only effects.

The turbine propulsion simulators are TDI model 441 simulators on loan from NASA Langley. Internal to the 441 , compressed air powers a threestage turbine, which drives the two-stage fan. The units are capable of producing $175 \mathrm{lbs}$ of thrust at 6.5 $\mathrm{lb} / \mathrm{s}$ total mass flow rate. The TPS units are heavily instrumented with thermocouples, total probes, and static ports, an accelerometer, and a RPM pick-up in 
order to permit thorough health monitoring during testing. In the case of a TPS unit failure, one back-up TPS unit had also been reconditioned and was available throughout the entire testing phase. Additionally, the TPS will never be operated at its maximum operating condition; it was projected that the running the units at a derated value (approximately $80 \%$ ) will extend the life of each unit, with the actual value at $78 \%$.

\section{F. Circulation Control Plenums}

Circulation control flow was delivered to the upper surface of the wing via eight separate wing plenums at the leading and trailing edges. Supplied by the low pressure system, each plenum has one small entrance which creates an uneven pressure distribution and vorticular flow. In order to reduce this complex flow, a thin partition of aluminum foam along with a low porosity metal mesh around the foam was used as a flow straightener. The purpose of the metal foam $/$ mesh combination was a means to achieve constant back pressure along the length of the plenum. Downstream of the aluminum foam is a converging nozzle. The throat of the nozzle varies in size (proportionally with the plenum) along the spanwise direction. Each slot plenum is instrumented with three pitot probes to measure the internal pressure to insure the plenum is at constant pressure during operation. Figure 7 shows a cross section of the leading and trailing edge plenums with the metal foam placement for scale.

In the past circulation control experiments have had issues with accurately predicting the flow has been precise knowledge of the slot height under pressure. The height of the circulation control slot is an important factor in the calculation of momentum coefficient, which is used widely in circulation control analysis. Cal Poly put forth a significant effort to understand the slot flow behavior prior to entering the wind tunnel test section. Reference 7 goes into the details of the slots flow uniformity and slot height measurements performed at the Fluid Mechanics Laboratory at Ames Research Center.
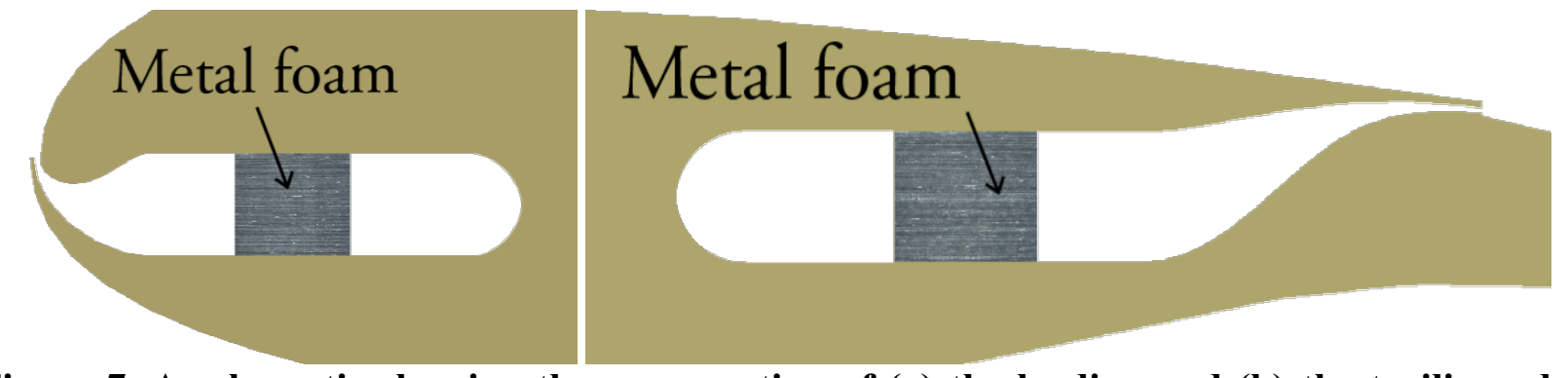

Figure 7. A schematic showing the cross section of (a) the leading and (b) the trailing edge plenums highlighting the meal foam flow straighter placement.

\section{G. Flow-Through Balance}

The MC-130-8.00-Ai air balance was utilized for the large scale wind tunnel test. The balance is being provided and calibrated by the Triumph Group. This particular balance is capable of operating with two separate flow systems at a maximum of $13 \mathrm{lb} / \mathrm{s}$ at $600 \mathrm{psi}$. AMELIA utilized only one flow system for the high pressure portion of the powered lift system. Table 1 details the original maximum allowable loads for the MC-130-8.00-Ai air balance, where all expected loads for AMELIA are within the allowable limits. 
Table 1. Original specifications for the MC-130-8.00-Ai air balance rated capacities (measured at the center of the balance)

\begin{tabular}{|c|c|c|c|c|c|}
\hline Normal & Pitching & Side & Yawing & Rolling & Axial \\
\hline Force (NF) & $\begin{array}{c}\text { Moment } \\
(\mathrm{PM})\end{array}$ & Force (SF) & $\begin{array}{c}\text { Moment } \\
(\mathrm{YM})\end{array}$ & $\begin{array}{c}\text { Moment } \\
(\mathrm{RM})\end{array}$ & Force (AF) \\
\hline \hline Lbs & in-lbs & Lbs & in-lbs & in-lbs & Lbs \\
\hline 13,000 & 107,250 & 3,000 & 18,000 & 32,000 & 500 \\
\hline
\end{tabular}

\section{H. Wind Tunnel Test Facility}

The National Full-Scale Aerodynamic Complex (NFAC) $40 \mathrm{ft}$ by $80 \mathrm{ft}$ wind tunnel was chosen to perform the large scale wind tunnel test. The NFAC offered several benefits over other large wind tunnels across the country, with the most significant being: the 10 foot model could be mounted on a sting which allows for cleaner measurements of the produced aerodynamic forces and moments, the tunnel could supply the high pressure air at the mass flow rate necessary to operate the $\mathrm{CCW}$ slots and the turbofan simulators, the tunnel is large enough such that the downwash created by the CCW wings would not impinge on the floor of the tunnel thus creating cleaner far-field acoustic measurements, the tunnel was acoustically treated such that aerodynamic and acoustic measurements could be performed simultaneously, and the NFAC's cost and schedule fit within Cal Poly's time frame and budget. Figure 8 shows a photograph of AMELIA mounted in the test section. The results and discussion section will show photographs of the smoke flow visualization effort confirming that downwash created by the powered lift systems does not impinge on the tunnel floor.

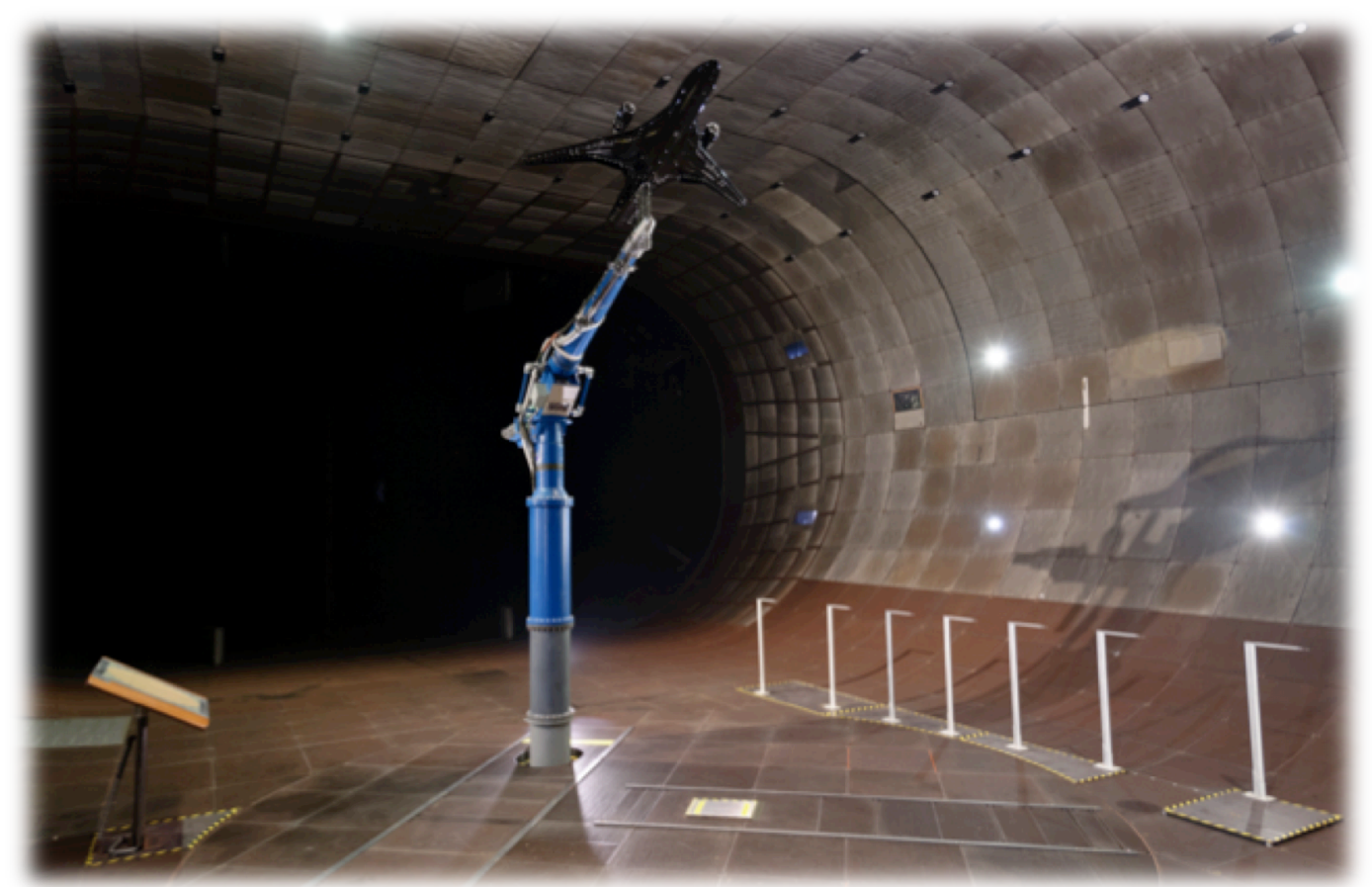

Figure 8. A photograph of AMELIA mounted in the $40 \mathrm{ft}$ by $80 \mathrm{ft}$ test section at the NFAC at Ames Research Center at the highest angle of attack tested $\left(+25^{\circ}\right)$. 


\section{AMELIA Instrumentation}

The purpose of AMELIA is to provide both aeroacoustic and aerodynamic measurements to be used for current and future modeling validation efforts. Therefore it's imperative that the model was highly instrumented in order to capture the maximum amount of flow physics possible for our given budget and timeline. Almost all instrumentation placement occurs on the left wing and was chosen based on preliminary CFD results. Figure 9 is a half-span schematic of the model illustrating the relative placement of the static pressure ports and unsteady pressure transducers. The model is instrumented with 230 static pressure ports in five chordwise groups and one spanwise group (highlighted in red in Fig. 9). The five chodewise locations were chose in order to investigate flow over the wing starting from the most inboard sections as follows: Buttline (BL) 118 captures the interactions between the fuselage and wing, BL 240 investigates the flow downstream of the engine exit plane, BL 500 should capture the flow over the wing with the least amount of inboard or outboard effects, and BL 638 and 642 are positioned close to one another for a direct comparison of pressure distribution on the outboard section of the wing with and without circulation control. The 8 unsteady pressure transducers were placed such that the cabin noise and the wing interaction downstream of the engine exit plane can be studied.

Five static pressure ports are located on the right wing in order to verify symmetry in the pressure distribution, this proved beneficial when determining when the wings had stalled at high angle of attack. The right half of the model was intentionally left as uninstrumented as possible to allow for global skin friction measurements using FISF, for more information about this technique for AMELIA please refer to Ref. 8. Reference 8 goes into detail of the measurement technique, the application of oil at the NFAC facility, and results of skin friction for several different operational runs.

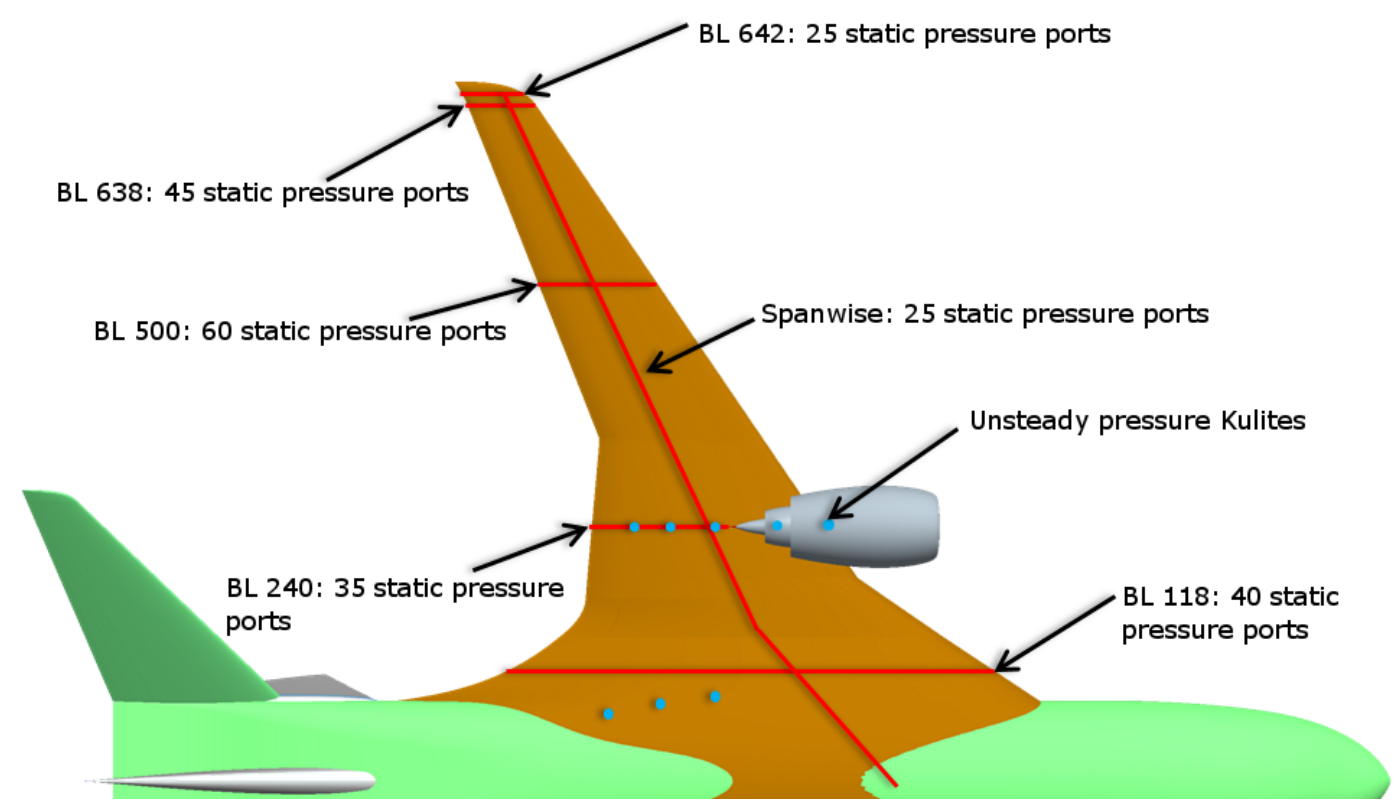

Figure 9. A schematic showing all external locations of the static pressure ports and the unsteady pressure transducers. 


\section{Test Parameters and Test Matrix}

\section{A. Wind Tunnel Test Facility}

The test parameters for the large-scale wind tunnel test included several different physical model changes as well as varying several operational set points for certain model components. Described in Table 2 is each variable parameter, mechanism, range, and the justification for each component and how it was manipulated. The engine height and circulation control flaps were physical model changes. The model changes were scheduled to have the least amount of impact to the schedule. With the exception of the critical test points (as explained in a following section), the flaps were changed at the end of a day while facility walk-throughs, maintenance, and general daily shut down operations were performed. The engine pylon height changes were significantly more involved and were performed only twice to minimize tunnel down time.

Wind tunnel speed, model attitude, engine simulator RPM, and circulation control mass flow were NFAC facility managed parameter changes. NFAC staff physically made the manipulations with oversight from the Cal Poly test team. Both the engine simulator set points and the circulation control set points were manipulated by increasing or decreasing the mass flow in the low and high pressure systems. The engine simulator RPM was directly related to the mass flow; the tunnel operator would adjust the mass flow and temperature of the high pressure system in order to set the RPM condition of the engine simulator.

Table 2. AMELIA Test Parameters.

\begin{tabular}{|c|c|c|c|}
\hline Parameter & Mechanism & Range & Justification \\
\hline Engine Height & $\begin{array}{l}\text { Mechanical: } \\
\text { model pylon change }\end{array}$ & $\begin{array}{l}\text { Low: } 2.75 \text { in } \\
\text { High: } 4.75 \text { in }\end{array}$ & $\begin{array}{l}\text { Investigate aerodynamic } \\
\text { and aeroacoustic impacts to } \\
\text { performance }\end{array}$ \\
\hline Engine Simulator RPM & $\begin{array}{l}\text { Pneumatic: } \\
\text { Tunnel mass flow }\end{array}$ & $\begin{array}{l}\% \text { to } 77 \% \\
\text { RPM to }\end{array}$ & $\begin{array}{l}\text { Investigate system } \\
\text { performance }\end{array}$ \\
\hline Model Attitude & $\begin{array}{l}\text { Mechanical: } \\
\text { sting pitch }\end{array}$ & $\begin{array}{l}-5 \text { degrees to }+25 \\
\text { degrees }\end{array}$ & $\begin{array}{l}\text { Investigate system } \\
\text { performance }\end{array}$ \\
\hline $\begin{array}{l}\text { Circulation Control } \\
\text { Mass Flow }\end{array}$ & $\begin{array}{l}\text { Pneumatic: } \\
\text { Tunnel mass flow }\end{array}$ & $\begin{array}{l}0 \% \text { to } 100 \% \\
\quad \mathrm{lbm} \text { to } 2.8 \mathrm{lbm}\end{array}$ & $\begin{array}{l}\text { Investigate system } \\
\text { performance }\end{array}$ \\
\hline $\begin{array}{l}\text { Circulation Control } \\
\text { Flaps }\end{array}$ & $\begin{array}{l}\text { Mechanical: } \\
\text { model flap change }\end{array}$ & \begin{tabular}{lc}
\multicolumn{2}{c}{ degrees } \\
3 & degrees \\
6 & degrees \\
8 & degrees
\end{tabular} & $\begin{array}{l}\text { Investigate circulation } \\
\text { control performance }\end{array}$ \\
\hline Wind Tunnel Speed & $\begin{array}{l}\text { Mechanical: } \\
\text { fan drive change }\end{array}$ & \begin{tabular}{l}
\multicolumn{2}{c}{ kts } \\
$4 \quad$ kts \\
6 kts \\
10 kts
\end{tabular} & $\begin{array}{l}\text { Investigate system } \\
\text { performance }\end{array}$ \\
\hline
\end{tabular}

The wind tunnel speed for the AMELIA test were chosen based on the engine simulator performance and model size. Figure 10 shows graph of the engine simulator thrust coefficient as function of tunnel speed and engine RPM. It was determined that the AMELIA test would investigate the model performance at a thrust coefficient of approximately 2.5. The largest portion of the test will focus on this thrust coefficient which leads to a tunnel speed of $40 \mathrm{kts}$. 
Two other tunnel speeds, 60 kts and 100 kts were also investigated to expand the experimental database.

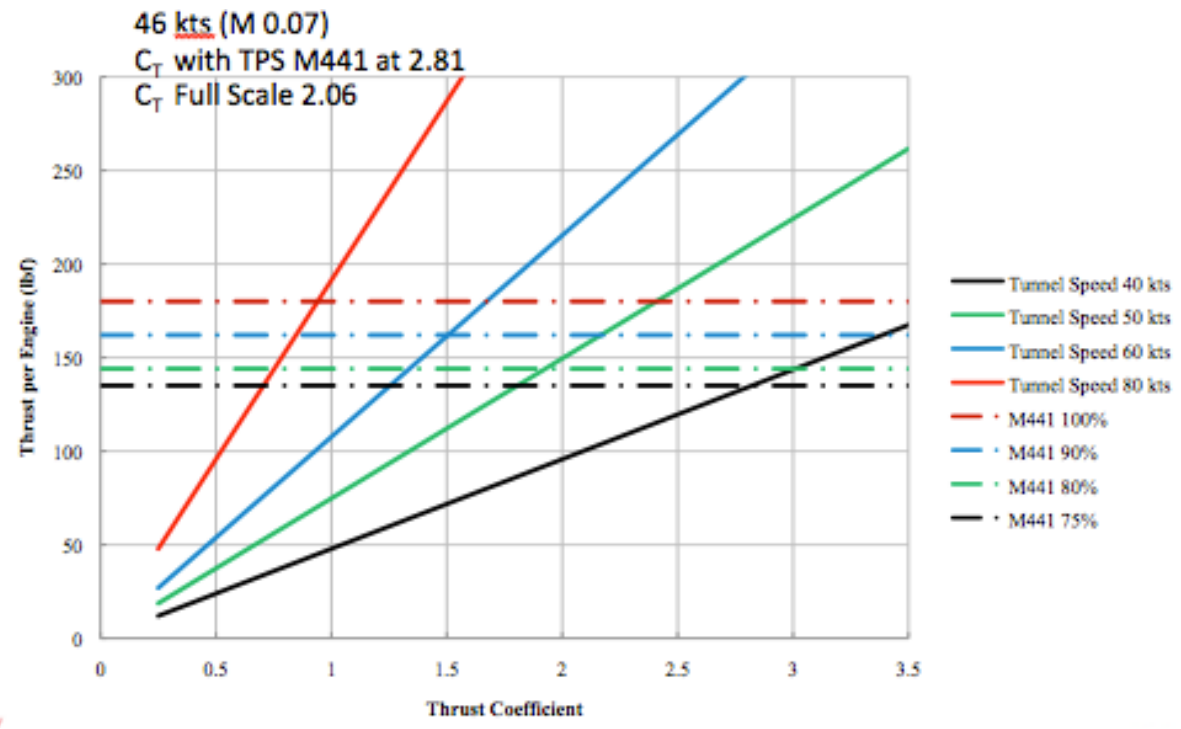

Figure 10. Engine simulator thrust coefficient as function of tunnel speed and RPM.

\section{B. AMELIA Test Matrix}

The tunnel time for the AMELIA test was scheduled to be 8-10 weeks permitting the final schedule and cost. The final time at the NFAC was approximately 8 weeks of wind on time not including an additional 5 weeks of model preparation in the test section. Tables 3 through 9 go into detail of the AMELIA test priorities, critical test points, test matrix runs, and the complete as-run test matrix.

The AMELIA test wanted to maximize the number of runs for a give model geometry and test priority. Table 3 states the final order in which the test was conducted, calling out the phases of the test from low engine pylon height, height engine pylon height, and the clean wing. The testing order described in Table 3 may not seam intuitive, however, based on the complexity of the model it was most efficient to start with the TPS units installed and then move to the clean wing configuration once all runs were conducted with the TPS. Due to the internal model design of the test equipment, once the TPS units were removed they could not easily be reintegrated back into the model.

During the test planning phase, taking into account all the test parameters and the test variables (schedule, cost, complexity) the test was going to be deemed a success if all 10 critical test points were obtained. The critical test points obtained the most diverse amount of experimental data (aerodynamic forces and moments, external surface pressures, skin friction, fairfield acoustic data, local noise, and on-body dynamic measurements) giving the numerical modeling community an limited but in depth experimental data set. However, as stated above, it was not practical to change engine heights during the critical test point phase, so the critical test points were split and taken with their prospective engine height. The general test matrix runs were also important to develop a broader database with a subset of the experimental measurements. The critical test points are shown in Table 4. 
Table 3. AMELIA Testing phases with associated engine heights.

\begin{tabular}{|l|l|}
\hline Phase & Mile Stones \\
\hline I - Low Engine Height & Baseline Runs \\
\hline I & 6 Critical Test Points \\
\hline II & Test Matrix Conditions \\
\hline III - High Engine Height & 3 Critical Test Points \\
\hline III & Test Matrix Conditions \\
\hline IV-Clean Wing & 1 Critical Test Point \\
\hline IV & Test Matrix Conditions \\
\hline
\end{tabular}

Table 4. AMELIA Critical Test Points.

\begin{tabular}{|c|c|c|c|c|c|c|c|c|}
\hline$\#$ & TS (kt) & alpha & beta & $C \mu$ & $\begin{array}{l}\text { Engine } \\
\text { Setting }\end{array}$ & flap & Eng. & Reason \\
\hline 1 & 100 & 0 & 0 & 0 & $0 \%$ & 0 & Low & Simple \\
\hline 2 & 40 & 0 & 0 & 0.36 & $77 \%$ & 80 & Low & $\begin{array}{l}\text { Diverted } \\
\text { Landing }\end{array}$ \\
\hline 3 & 60 & 5 & 0 & 0.36 & $20 \%$ & 80 & Low & Landing \\
\hline 4 & 60 & 5 & 0 & 0.18 & $77 \%$ & 60 & Low & Takeoff \\
\hline 5 & 40 & 5 & 0 & 0.10 & $77 \% / 30 \%$ & 60 & Low & OEI (1) \\
\hline 6 & 40 & 5 & 0 & 0.10 & $30 \% / 77 \%$ & 60 & Low & OEI (2) \\
\hline 7 & 100 & 0 & 0 & 0 & $0 \%$ & 0 & High & Simple \\
\hline 8 & 40 & 0 & 0 & 0.36 & $77 \%$ & 80 & High & $\begin{array}{l}\text { Diverted } \\
\text { Landing }\end{array}$ \\
\hline 9 & 60 & 5 & 0 & 0.36 & $20 \%$ & 80 & High & Landing \\
\hline 10 & 60 & 5 & 0 & 0.18 & $0 \%$ & 60 & Clean & Baseline \\
\hline
\end{tabular}

Once the model had been mounted into the test section, checked out, and calibrated several preruns were taken to insure the quality of data obtained during the test would be satisfactory as well as setting a baseline for data comparison. The AMELIA steps were as follows (not necessary in order):

1. Static tests of all blown features on the model

2. Reynolds number sweep

3. Dynamic pressure sweep

4. Turbofan propulsion simulator sweep

5. Circulation control mass flow sweep

6. Repeat test points 
After the completion of the preliminary and baseline sweeps, the critical test points were obtained (as shown in Table 3), and then the test matrix points were obtained. Tables 5, 6, and 7 show the text matrix runs for the low engine height, high engine height, and the clean wing, respectively. The test matrix runs were designed to change one model parameter at a time, starting with the parameter that needed the lease about of time to physically modify. Not shown in Tables 5 through 7 are (1) the sideslip sweeps were taken for only one tunnel speed and one flap deflection at each engine configuration, as it was projected that the difference in the sideslip would not be significant for each engine configuration. (2) Circulation control mass flow sweeps were taken at each engine configuration for a constant angle of attack of $-5^{\circ}, 0^{\circ}$ and $+10^{\circ}$. Table 5 also shows measurements taken at the $30^{\circ}$ flap configuration. Only a limited data set was taken at the $30^{\circ}$ flap configuration, as it was not the main focus of the test, however it does provide additional data and allows for a more detailed comparison of flap setting and system performance at the $40 \mathrm{kt}$ condition.

Table 5. Phase II: Low engine height test matrix.

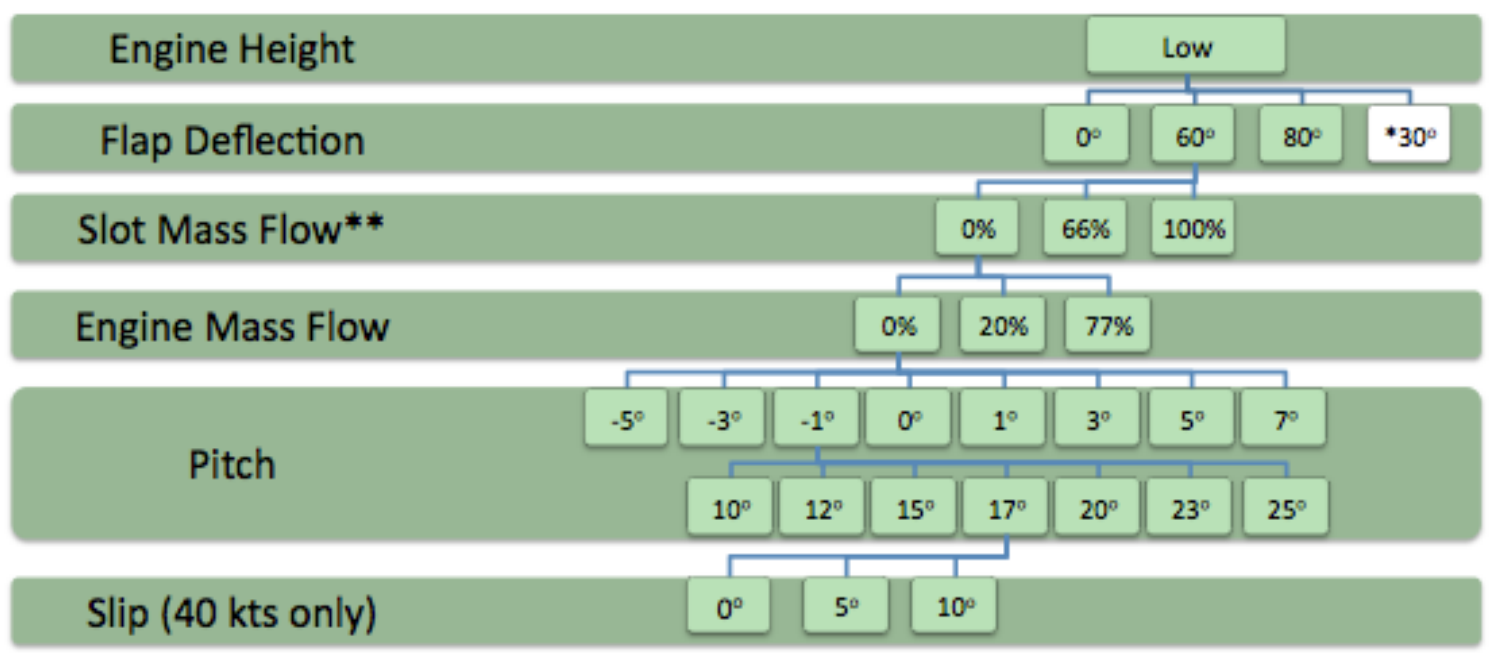

Table 6. Phase III: High engine height test matrix.

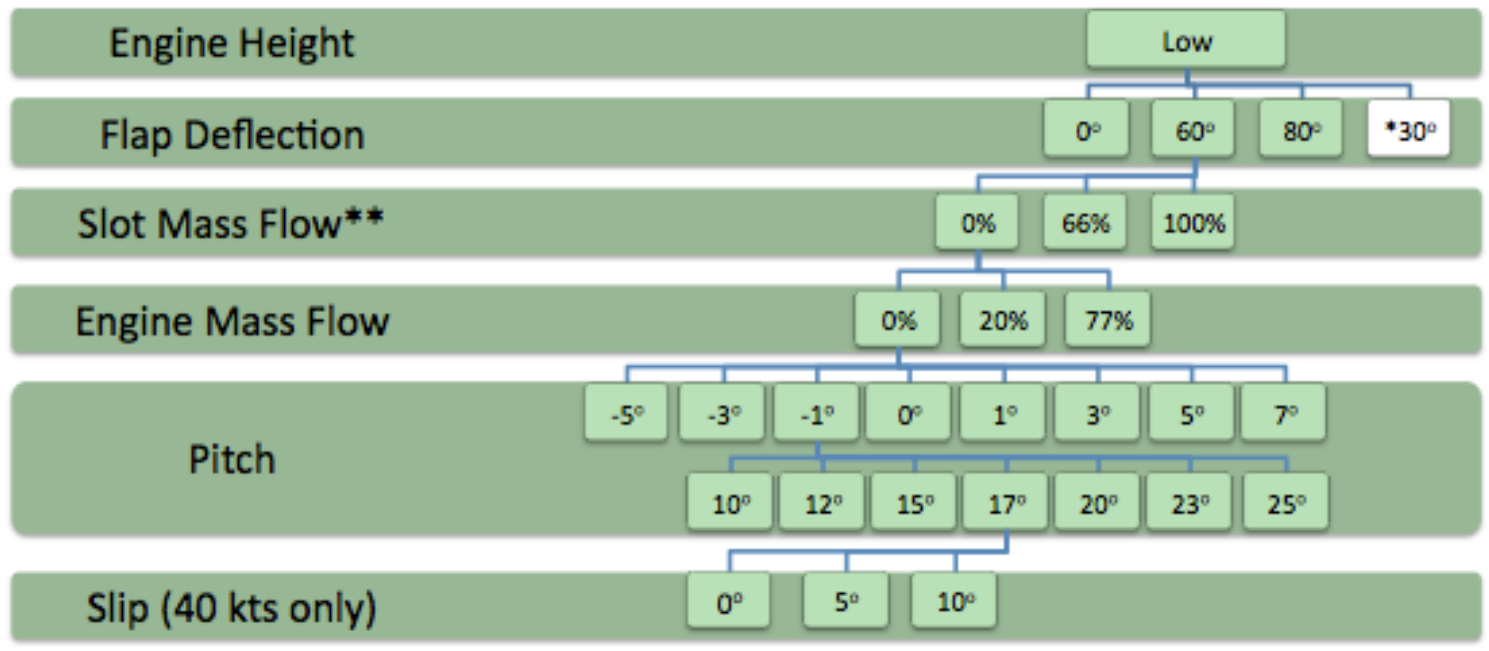


Table 7. Phase IV: Clean wing test matrix.

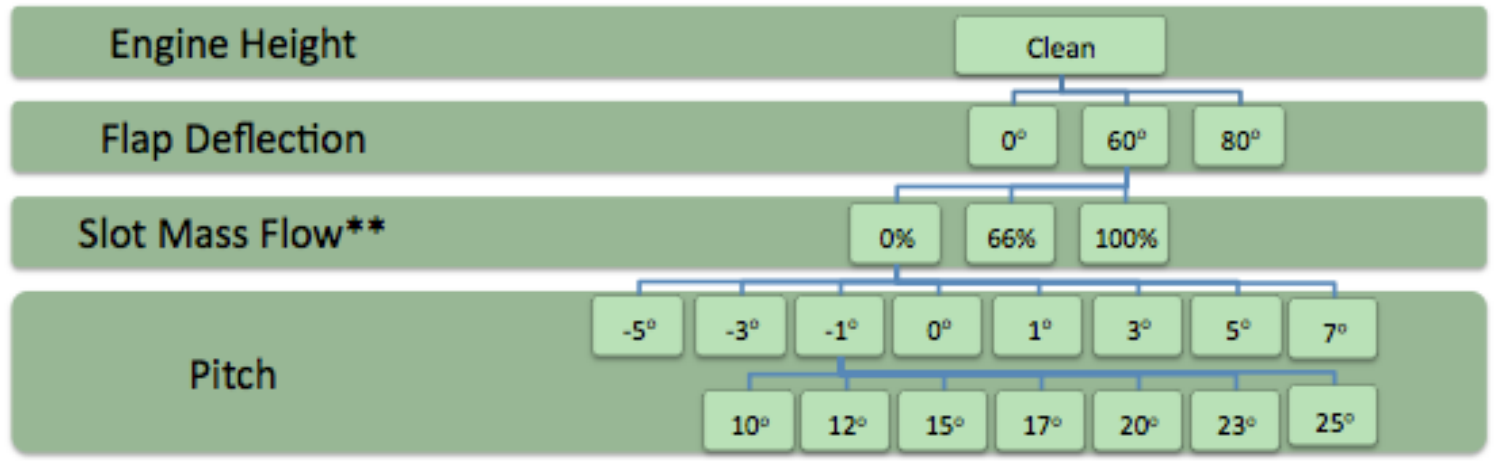

The AMELIA test was over all was able to meet its entire set of objectives stated in Table 3. Tables 8 and 9 give summaries of the AMELIA test, were Table 8 summarized the number of days spent in model preparation, model installation, test execution, and model removal and Table 9 summaries the wind-on portion of these highlighting the number of useful data runs achieved at each engine height. Additional funds were requested from Subsonic Fixed Wing Project to support additional tasks during the wind-on portion of the test. These additional funds allowed Cal Poly to obtain additional test matrix data points, specifically the high engine height and all data at the clean wing configurations.

Table 8. AMELIA Test summary.

\begin{tabular}{|l|c|c|}
\hline Task & Planned Duration (days) & Actual Duration (days) \\
\hline Model Support Installation & 10 & 9 \\
\hline Sting-Only Runs & 2 & 1 \\
\hline $\begin{array}{l}\text { Model/Instrumentation } \\
\text { Installation }\end{array}$ & 2 & 9 \\
\hline Instrumentation Checkout & 7 & 9.5 \\
\hline HPA Checkout & 5 & 2.5 \\
\hline Holiday Stand-Down & 0 & 5 \\
\hline Wind-On Testing & 30 & 30.5 \\
\hline Removal & 5 & 5 \\
\hline Total & 61 & 71.5 \\
\hline
\end{tabular}


Table 9. AMELIA wind-on test summary.

\begin{tabular}{|c|c|c|c|c|}
\hline Model Configuration & Runs & Useful Data Runs & Calendar Days & Wind-on Days \\
\hline Low Pylon & $18-171$ & 151 & $\begin{array}{c}12 / 21 / 2011- \\
1 / 27 / 2012\end{array}$ & 20 \\
\hline High Pylon & $172-203$ & 29 & $\begin{array}{c}1 / 30 / 2012- \\
2 / 3 / 2012\end{array}$ & 5 \\
\hline Clean Wing & $204-270$ & 64 & $\begin{array}{l}2 / 6 / 2012- \\
2 / 10 / 2012\end{array}$ & 5 \\
\hline TE-only Blowing & $271-312$ & 41 & $\begin{array}{c}2 / 14 / 2012- \\
2 / 15 / 2012\end{array}$ & 2 \\
\hline Total User Occupancy Hours & \multicolumn{4}{|c|}{617.5} \\
\hline $\begin{array}{l}\text { Total Wind-On Calendar } \\
\text { Time }\end{array}$ & \multicolumn{4}{|c|}{$12 / 21 / 2011-2 / 15 / 2012$} \\
\hline
\end{tabular}

As a part of any test, there are unforeseen facility issues that can cause delays during the test execution phase. However, the facility down time was very minimal (approximately 13.5\% of test execution) and significantly added in the efficiency of the AMELIA test. During the wind-on portion of the test, Cal Poly was able to record all 10 critical test points, over 280 useful data runs in the test matrix phases, and add in successful oil flow and smoke flow visualization runs.

\section{Results Overview}

A general overview of select wind tunnel results is provided here. For a more in-depth evaluation, see Ref. 4. Data acquired during an alpha sweep were generally obtained over a range from $-5^{\circ}$ to $+25^{\circ}$. Runs at high power conditions that saw considerable model vibrations were held to a smaller positive alpha limit. This limit was subjective and dependent on the magnitude of the vibrations. During an alpha sweep, the model is held at a fixed slot and TPS power setting and swept through the angle of attack range. For reference, the nominal slot mass flow rate is 2.8 $\mathrm{lb}_{\mathrm{m}} / \mathrm{sec}$ and the nominal TPS RPM is 34,500 .

\section{A. Trailing Edge-Only Blowing Configuration}

The trailing edge-only blowing model configuration data were acquired over the final 2 days of wind-on testing. In this configuration, the TPS are removed and the leading-edge plenums have been blocked at the downstream side of the butterfly valves. The data in this configuration are limited to the $0^{\circ}$ and $60^{\circ}$ flap deflections. The trailing-edge plenum pressures are matched between this configuration and the combined leading- and trailing-edge blowing runs.

Representative model performance in the trailing edge-only blowing configuration is seen in Figs. 11 through 13. The figures show model performance as augmented by increasing blowing at a fixed flap deflection. In general, lift and pitch moment are increased with blowing. For a fixed flap deflection, the addition of blowing decreases the stall angle due to the inability of the flow to maintain attachment around the leading-edge as the up-wash increases due to the blowing-induced circulation. With the $60^{\circ}$ flap deflection, the locus of stall points moves to 
smaller angles as the momentum coefficient is increased. At the highest blowing condition, stall is seen to occur at $0^{\circ}$ angle of attack. The drag data for the $0^{\circ}$ flap deflection shows a slot thrust as momentum coefficient is increased; this is not seen with the positive flap deflections as the direction of the jet leaving the slot is no longer in line with the drag axis, as seen in Fig. 12.

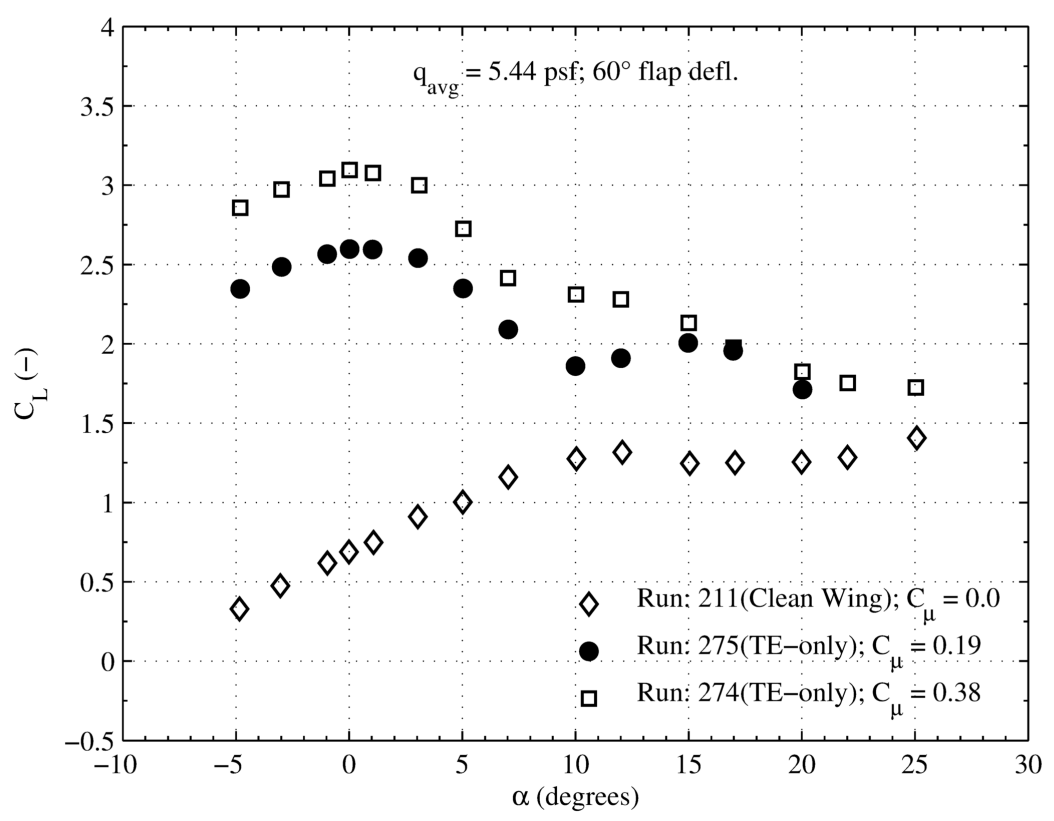

Figure 11. Coefficient of lift verses angle of attack for trailing edge only blowing at 40 KTS and $60^{\circ}$ flap deflection.

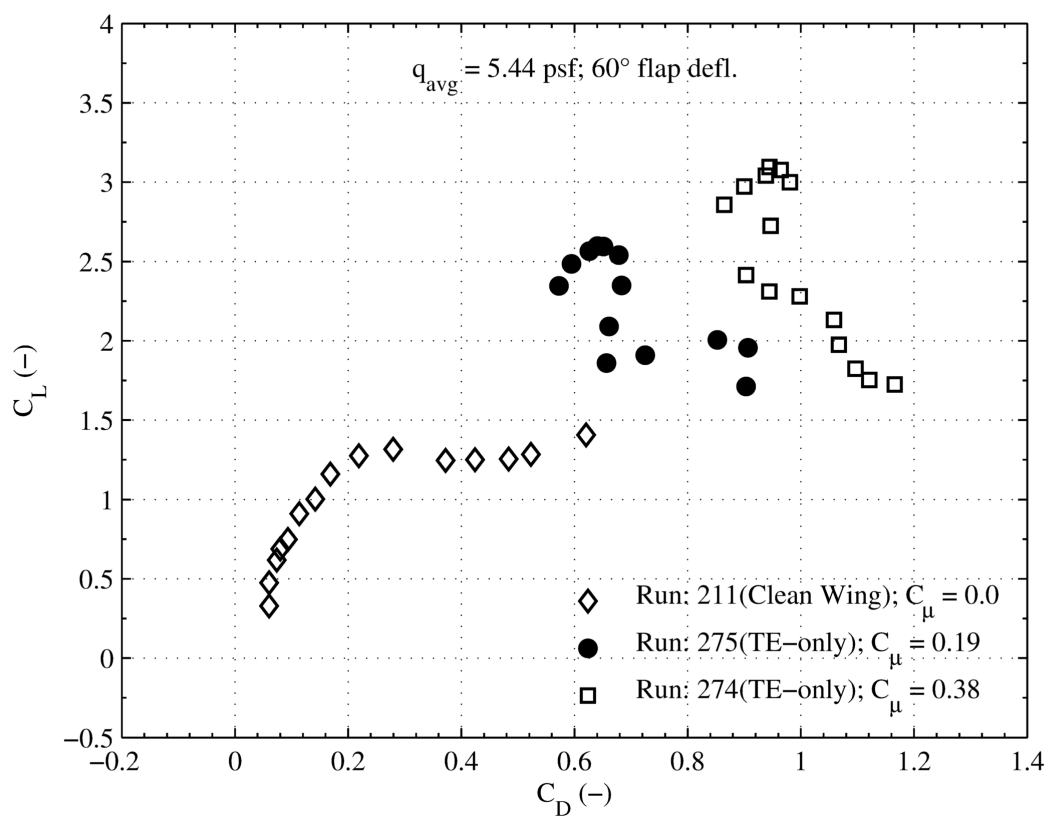

Figure 12. Coefficient of lift verses coefficient of drag for trailing edge only blowing at $40 \mathrm{KTS}$ and $60^{\circ}$ flap deflection. 


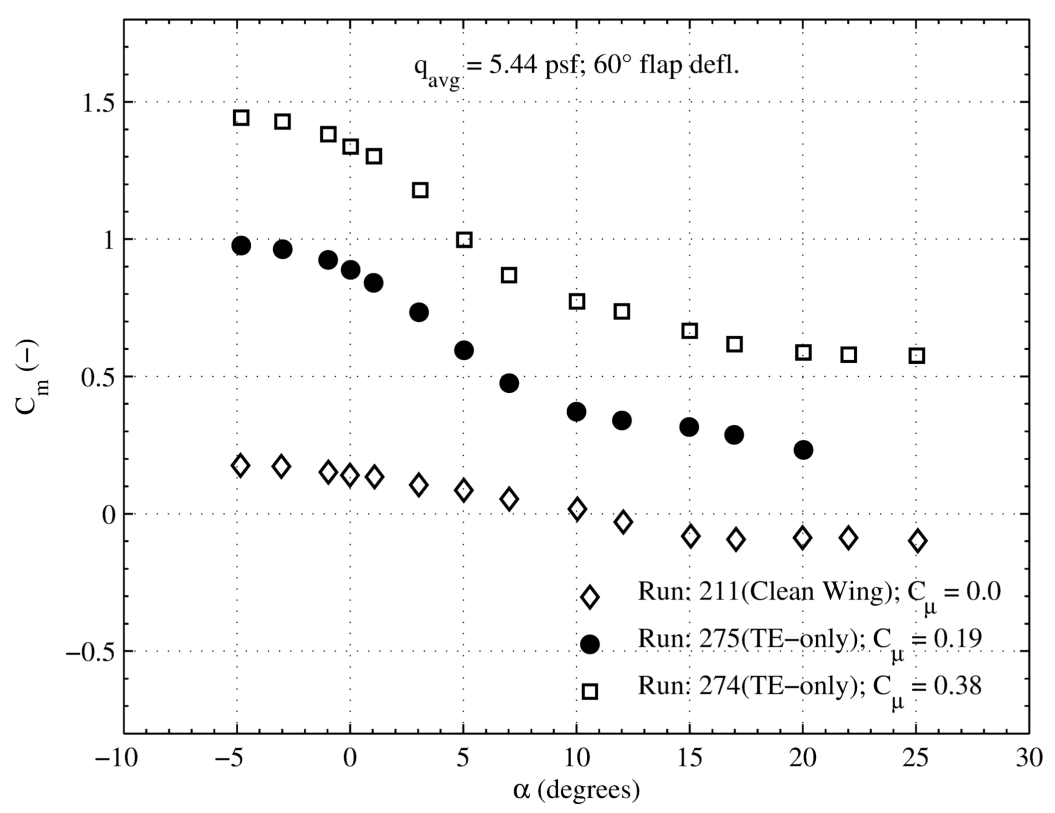

Figure 13. Pitching moment verses angle of attack for trailing edge only blowing at 40 KTS and $60^{\circ}$ flap deflection.

\section{B. Clean Wing Configuration}

Originally, testing was only planned for the low- and high-pylon heights. Clean wing runs were added late in the test planning phase by sacrificing low pylon runs at the $30^{\circ}$ flap deflection. The decision was justified because of the value the clean wing runs provide to the CFD community.

Figures 14-16 present data acquired during slot sweeps. Data are provided at a fixed tunnel speed and flap deflection, with curves for multiple angles of attack. Here, with leading- and trailing-edge blowing, lift continues to increase as angle of attack is increased. The region at low blowing where the increase in $\mathrm{C}_{\mathrm{L}}$ with each increment of blowing is the highest is referred to as the separation control region. The separation control region is where the separation point is quickly moved to the trailing-edge as blowing is increased. A momentum coefficient less than 0.1 characterizes this region, seen in Fig. 14. Beyond this region is the super circulation region. Here, lift continues to increase but it is not as efficient because the separation point has been fixed at the trailing edge of the flap. For the $60^{\circ}$ flap deflection, drag is positive and increases with blowing across the three angles of attack. Figure 16 shows decreasing pitching moment with angle of attack. 


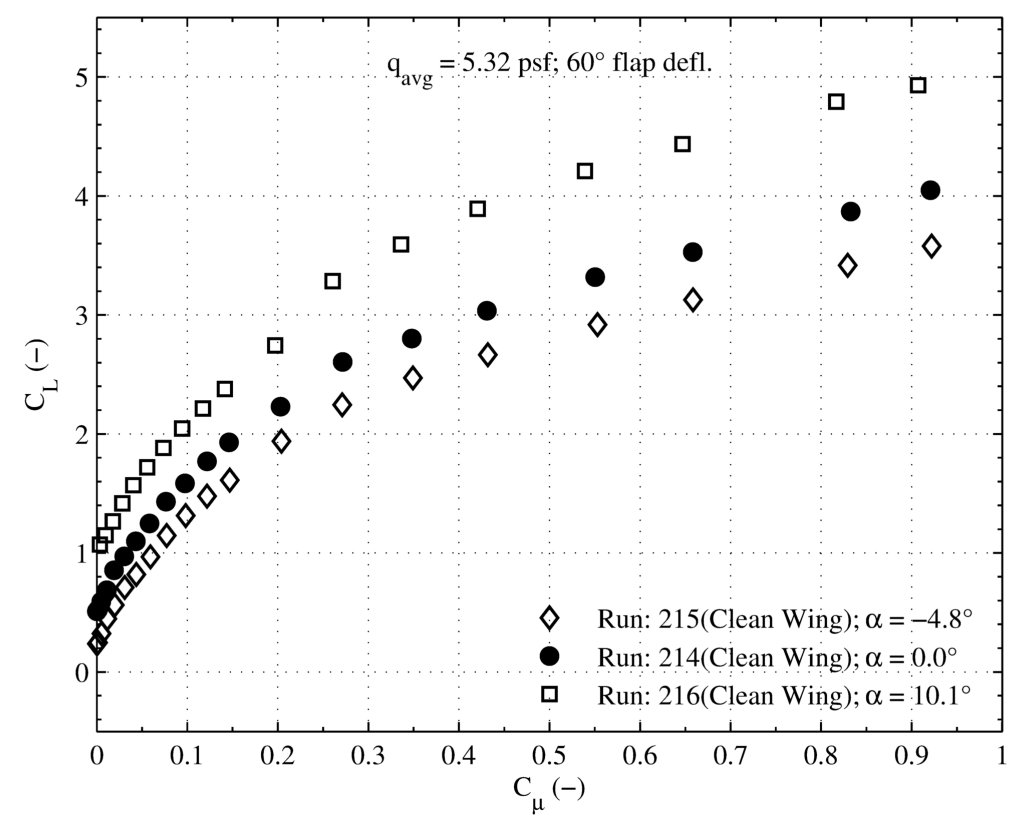

Figure 14. Coefficient of lift verses momentum coefficient for the clean wing configuration at $40 \mathrm{KTS}$ and $60^{\circ}$ flap deflection.

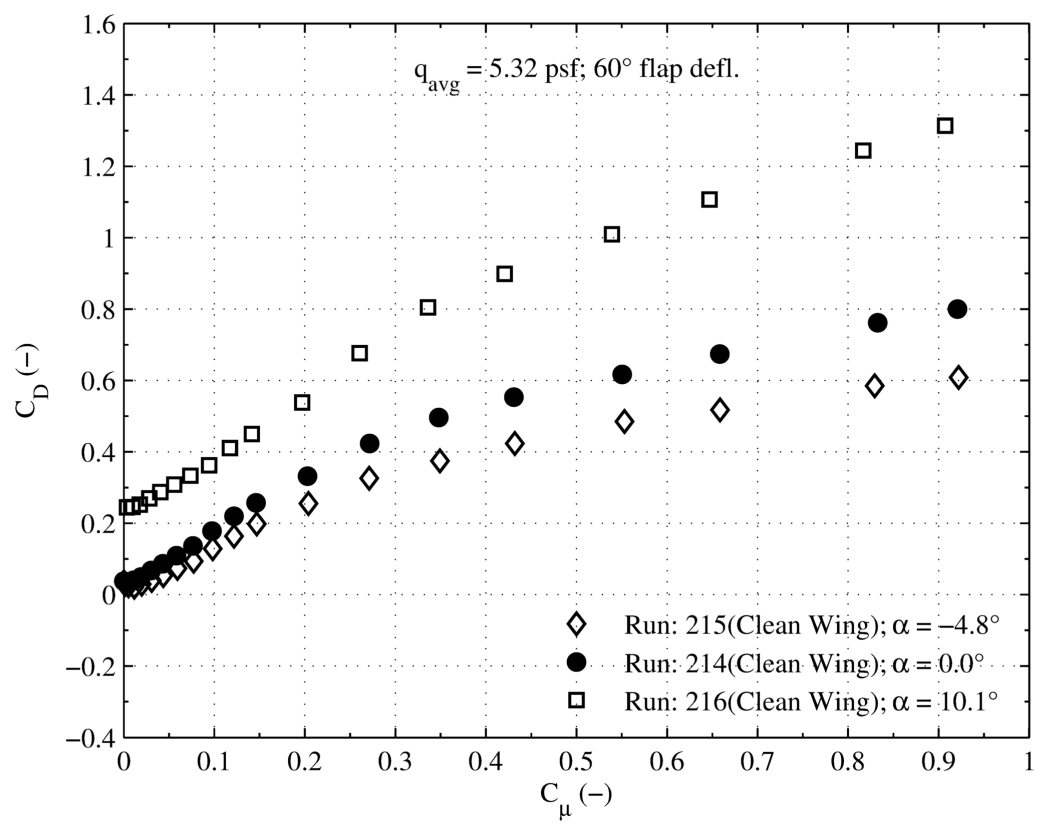

Figure 15. Coefficient of drag verses momentum coefficient for the clean wing configuration at $40 \mathrm{KTS}$ and $60^{\circ}$ flap deflection. 


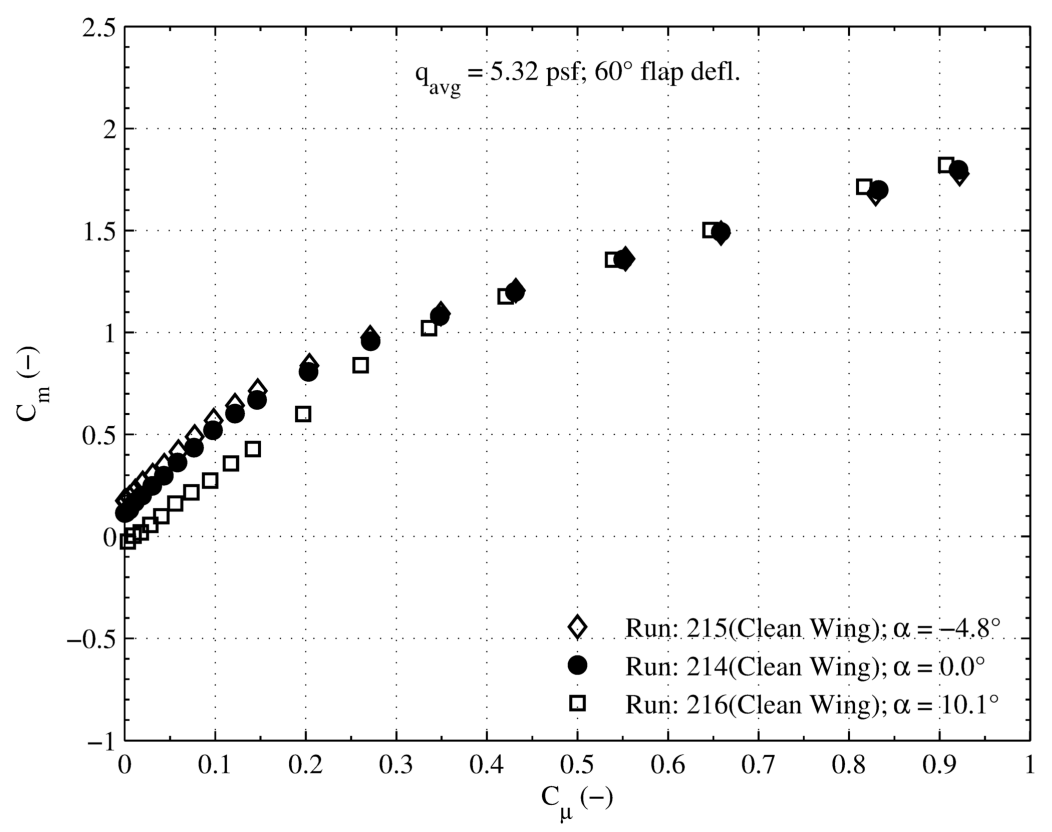

Figure 16. Pitching moment verses momentum coefficient for the clean wing configuration at $40 \mathrm{KTS}$ and $60^{\circ}$ flap deflection.

\section{Low Pylon Height Configuration}

The data presented with the TPS-on is left uncorrected. As a result, the thrust component is present and results in a negative drag value due to the alignment of the drag axis with the local freestream vector. The addition of the engine thrust increases the lift curve slope because of the thrust component. The increase in lift when the engine simulators is on is not so much due to the thrust deflection angle, but more due to the increased wing upper surface velocities and resulting decreased static pressures. In general though, larger lift augmentation is achieved from increasing momentum coefficient rather than increasing TPS thrust.

Figures 17-19 present aerodynamic data for varying flap deflections at $100 \mathrm{KTS}$ and the full powered lift condition. With the TPS-on at high blowing and angle of attack, the $80^{\circ}$ flap cannot maintain lift augmentation over the $60^{\circ}$ flap. The low pylon doesn't appear overly strong at deflecting engine exhaust at high flap deflections. This is predominately seen at this high speed where stall is seen around $10^{\circ}-12^{\circ}$. The addition of TPS thrust delays stall from $7^{\circ}$ to $13^{\circ}$, compared to the clean wing sweeps. As was seen in the other configurations, drag and pitching moment increase as the flap deflection increases. Figure 18 shows increasing drag as flap deflection is increased, with slot thrust from the $0^{\circ}$ flap. 


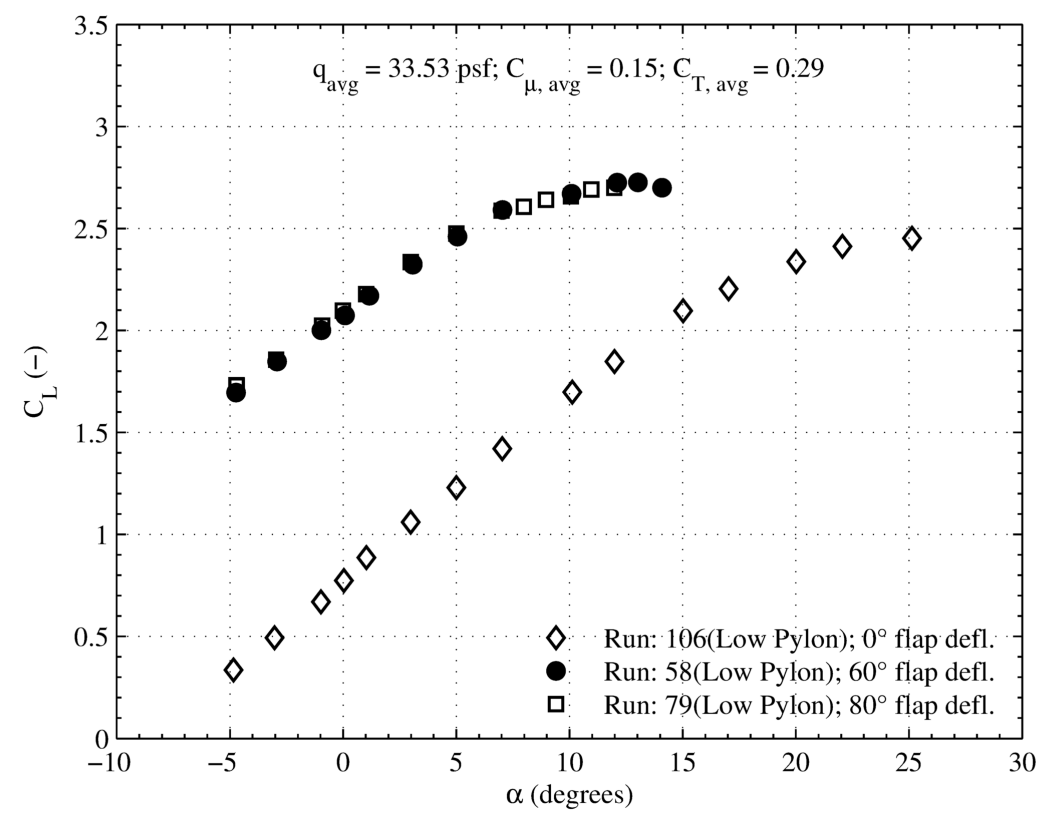

Figure 17. Coefficient of lift verses angle of attack for the low pylon configuration at $100 \mathrm{KTS}$ at the full powered condition.

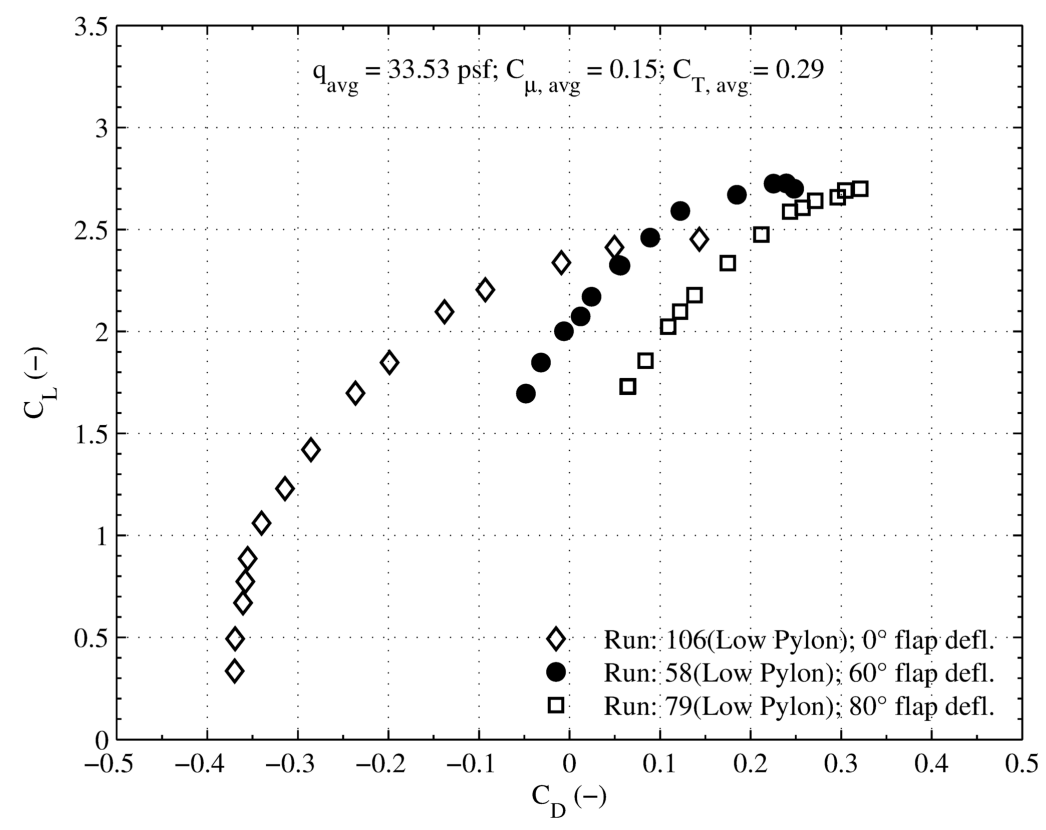

Figure 18. Coefficient of lift verses coefficient of drag for the low pylon configuration at $100 \mathrm{KTS}$ at the full powered condition. 


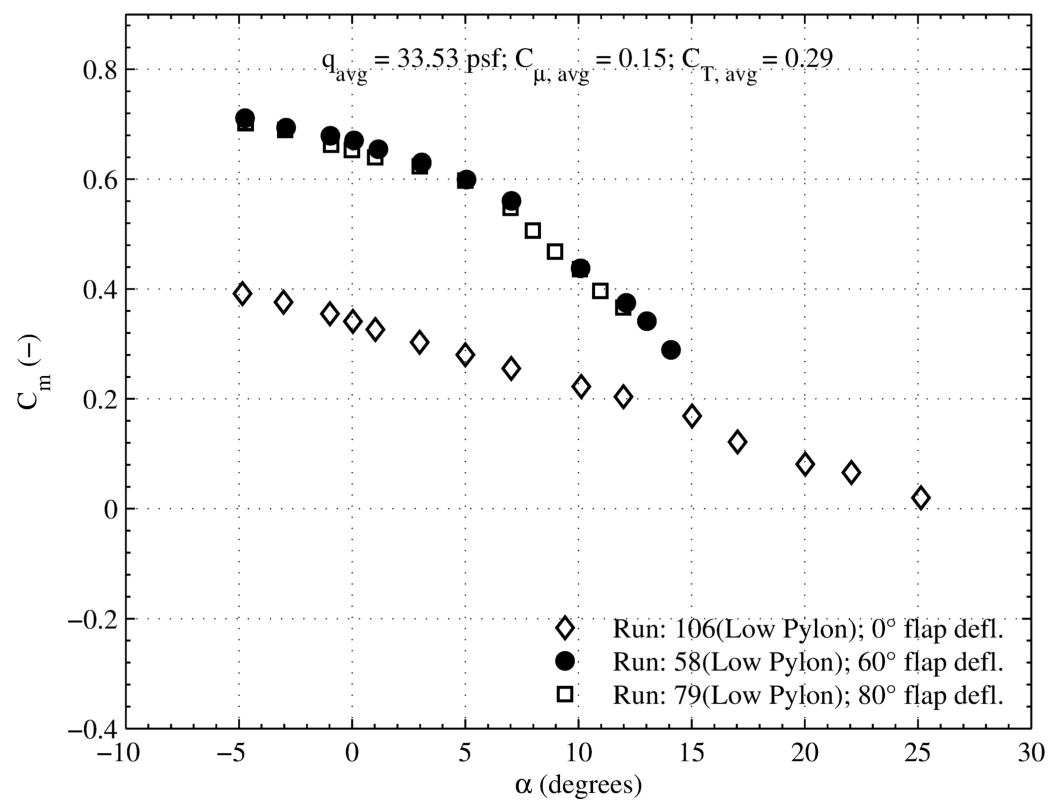

Figure 19. Pitching moment verses angle of attack for the low pylon configuration at 100 KTS, at the full powered condition.

\section{High Pylon Height Configuration}

Figures 20-22 present alpha sweeps for each point in the powered-lift matrix at $40 \mathrm{KTS}$ in the $80^{\circ}$ flap deflection. Figure 20 shows the performance benefits from deflecting the engine exhaust are seen predominately at higher angles of attack. The increase in lift is not so much due to the thrust deflection angle, but more so the increased upper surface velocities that result. As expected, each point in the powered-lift matrix is additive with respect to increasing the fullpowered lift coefficient. At $25^{\circ}$ angle of attack, the maximum lift coefficient is increased by just over 1 to 6.5 with the engine simulators at the nominal set-point. Again, the lift curve is increased because of the thrust component being present in the data. In Fig. 21, the positive flap deflection does not provide slot thrust, hence the larger (positive) drag when the slots are blowing. The thrust recovery from the thrust coefficient component is also seen in the figure. Figure 22 shows that the application of both TPS thrust and slot flow are additive components to the total pitching moment.

For reference, the high pylon height measures 6.26 inches from the wing upper surface to the TPS centerline; the low pylon measures 4.21 inches along the same reference. 


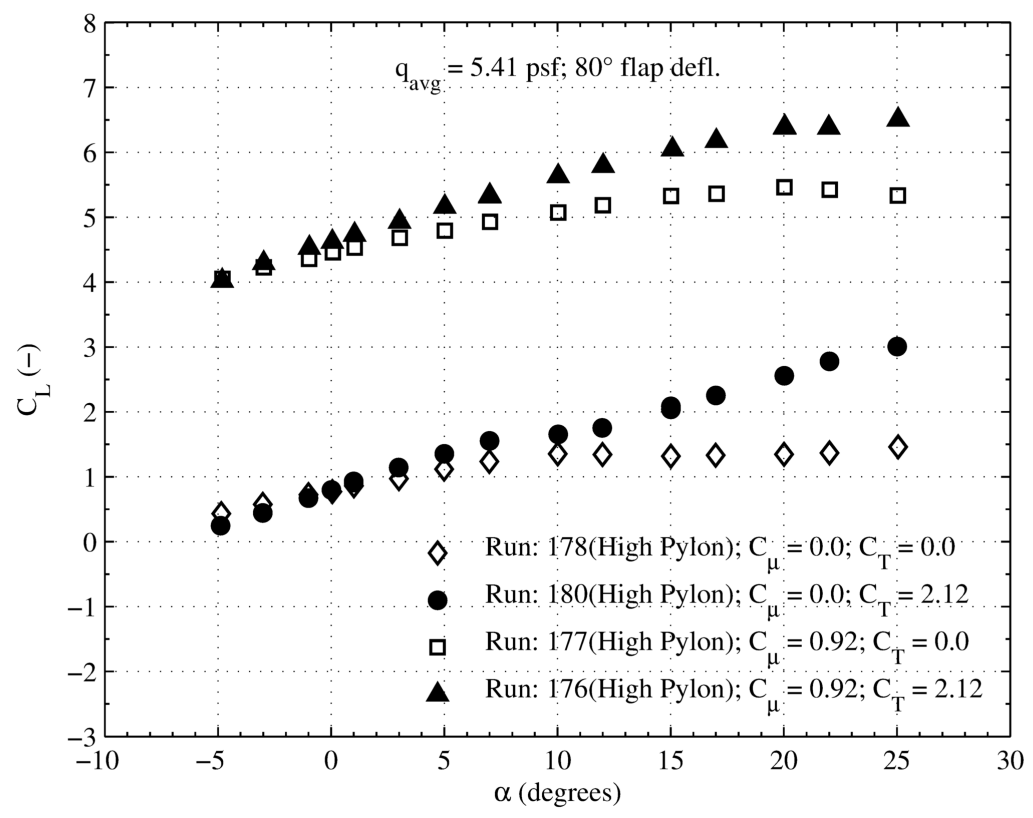

Figure 20. Coefficient of lift verses angle of attack for the high pylon configuration at $40 \mathrm{KTS}$ and $80^{\circ}$ flap deflection.

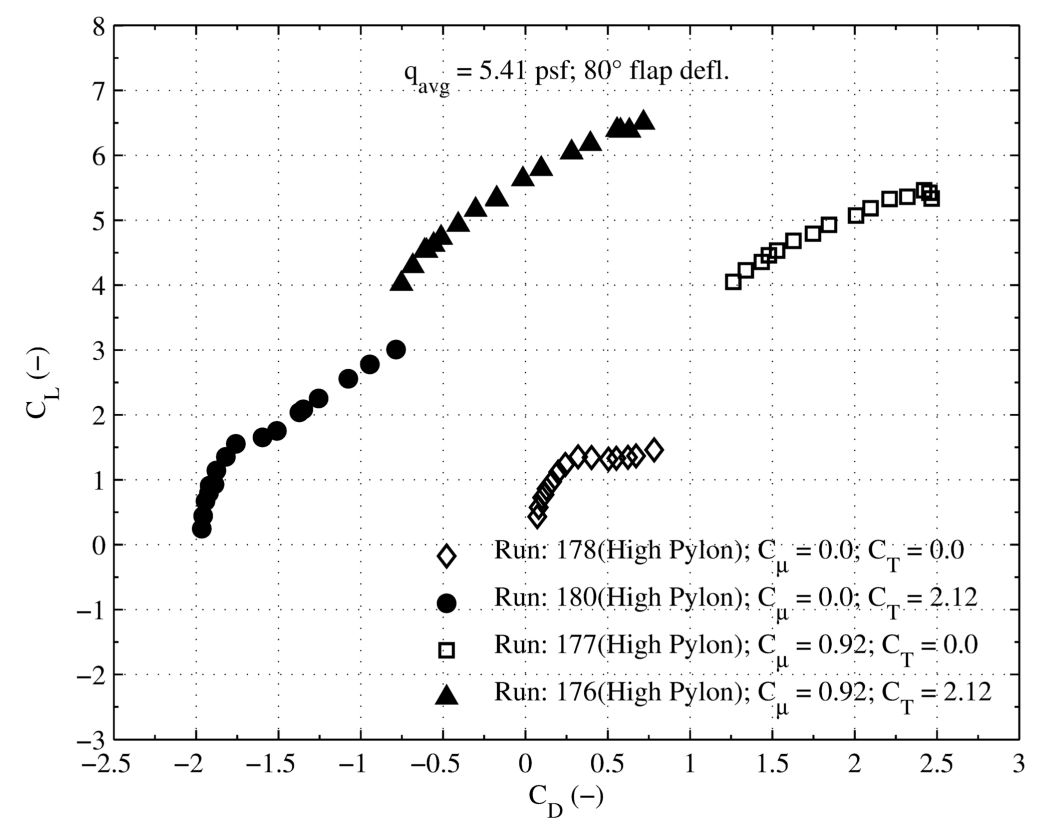

Figure 21. Coefficient of lift verses coefficient of drag for the high pylon configuration at $40 \mathrm{KTS}$ and $80^{\circ}$ flap deflection. 


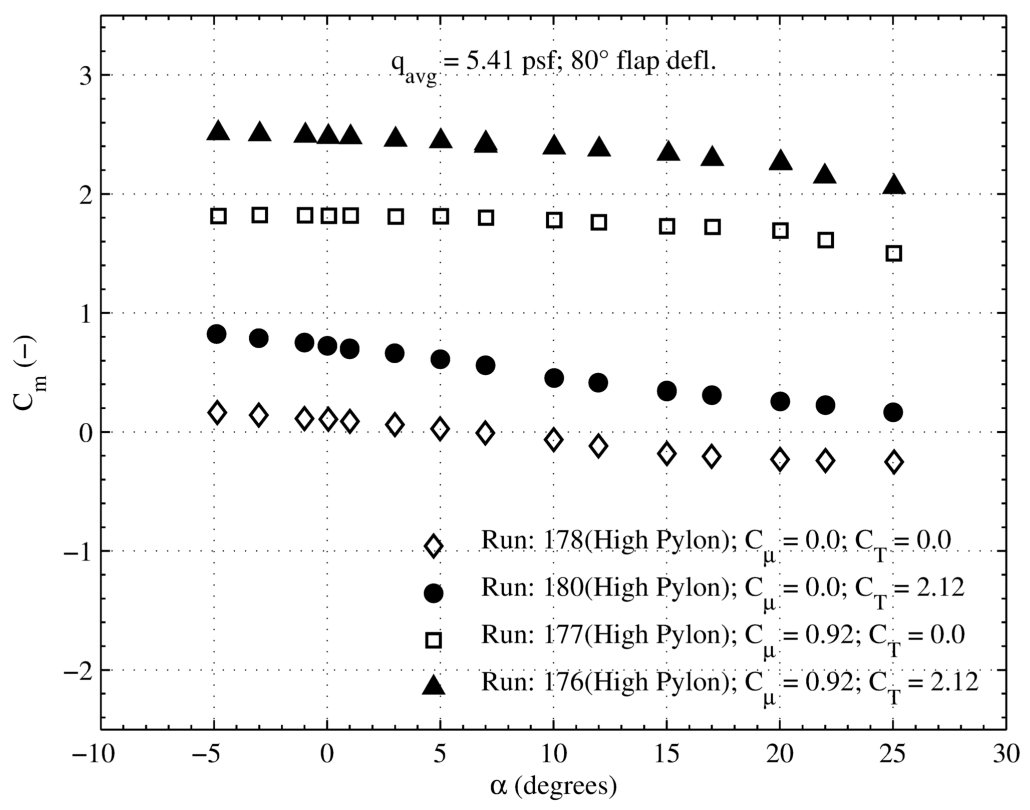

Figure 22. Pitching moment verses angle of attack for the high pylon configuration at 40 KTS and $80^{\circ}$ flap deflection.

\section{Flow Visualization}

During the low engine height configuration phase of the test matrix, two flow visualization techniques were employed to obtain qualitative data on the powered lift performance of AMELIA. Figure 23 shows a smoke streamline at a tunnel speed of $30 \mathrm{kts}$ with a momentum coefficient at 0.8 ; this figure qualitatively shows that the downwash created for the circulation control wing does not impinge on the tunnel floor giving the Cal Poly test team confidence in the modeling predictions and assurance that the far field acoustic measurements will not be adversely affected by the downwash. Also, shown in Fig. 23 is the scale of the downwash, the predicted effect was approximately one full span $(\sim 10 \mathrm{ft})$ from the bottom surface of the wing; the smoke contrail roughly follows the prediction.

The Cal Poly test team was allowed to be in the wind tunnel test section during nominal operation at $30 \mathrm{kts}$ without wavers. Although, the $30 \mathrm{kt}$ wind tunnel speed was not a part of the wind tunnel test matrix, helpful qualitative photographs were obtained using the smoke flow visualization technique. Figure 24 shows the smoke contrails for increasing momentum flow (from momentum coefficients of 0.0 to 0.8 ) through the circulation control wing again at $30 \mathrm{kts}$, clearly illustrating the effects of circulation control. Figure 24 is unique in that the photographs verify that the flow over the wing is entrained with increased momentum flow through the slots.

Oil flow visualization was also employed while in the test section at the NFAC. Due to the time consuming nature of the technique, a very limited data set was obtained. Figures 25 and 26 are from the nominal $40 \mathrm{kt}$ full $\mathrm{CCW}$ power operational condition (the circulation control wings were operated at 0.8 momentum coefficient). Figure 25 verifies that the flow exiting the circulation control wing plenums (both leading edge and trailing edge) is straight. Also shown in Fig. 25 is the flow downstream of the engine simulators does not give any valid data, due to the bearing lubrication exiting the back of the TPS units. Figure 26 is a photograph of the outboard 
section of wing using the oil flow method; showing that at the wing tip the momentum flow from the CCW plenum is not sufficient to keep the flow attached to the wing tip surface.

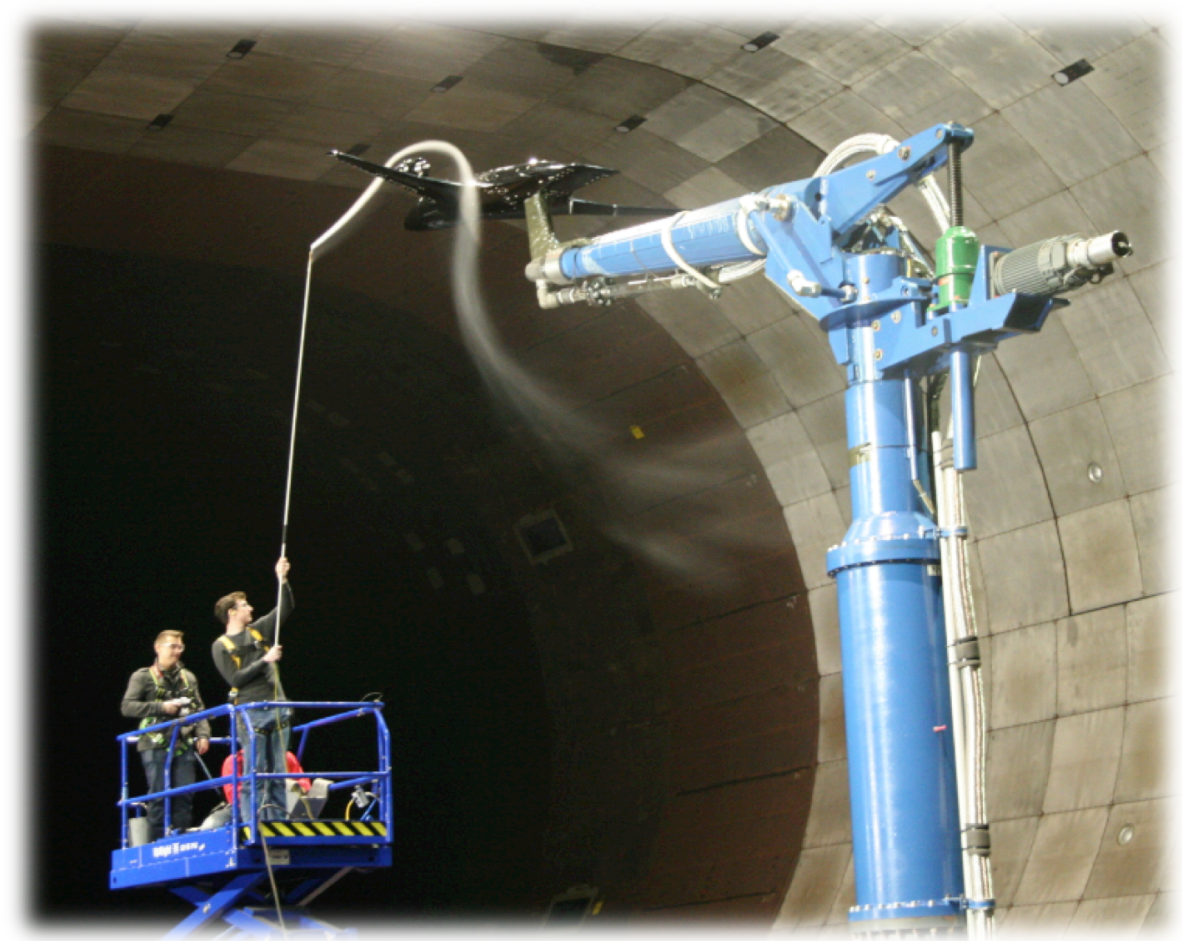

Figure 23. A smoke contrail of the circulation control wing of the powered lift system on AMELIA at 30 KTS at a momentum coefficient of 0.8 .
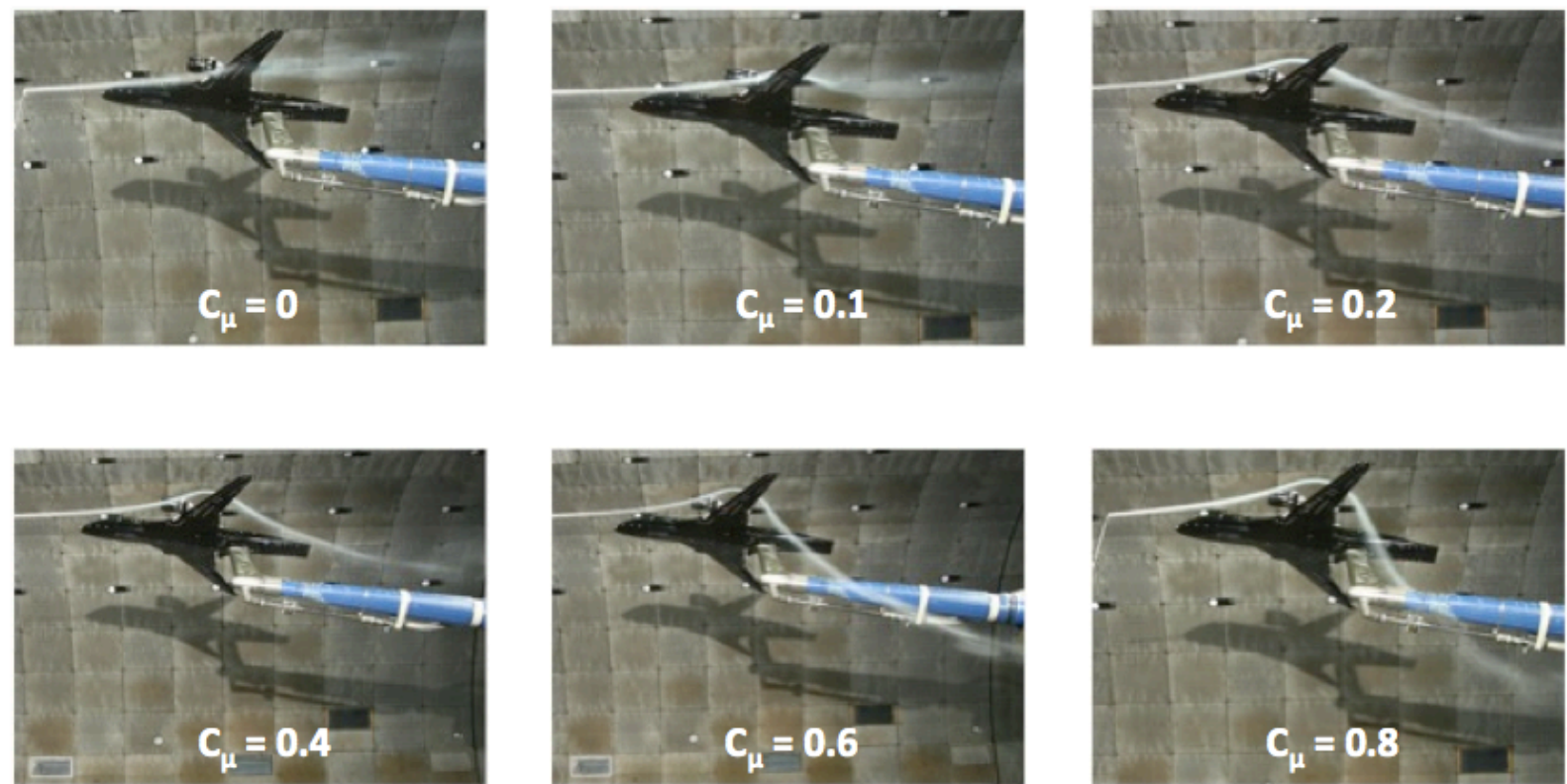

Figure 24. Smoke contrails of the circulation control wing of the power lift system on AMELIA for increasing momentum flow, with a momentum coefficient increased from 0.0 to a maximum of 0.8 . 


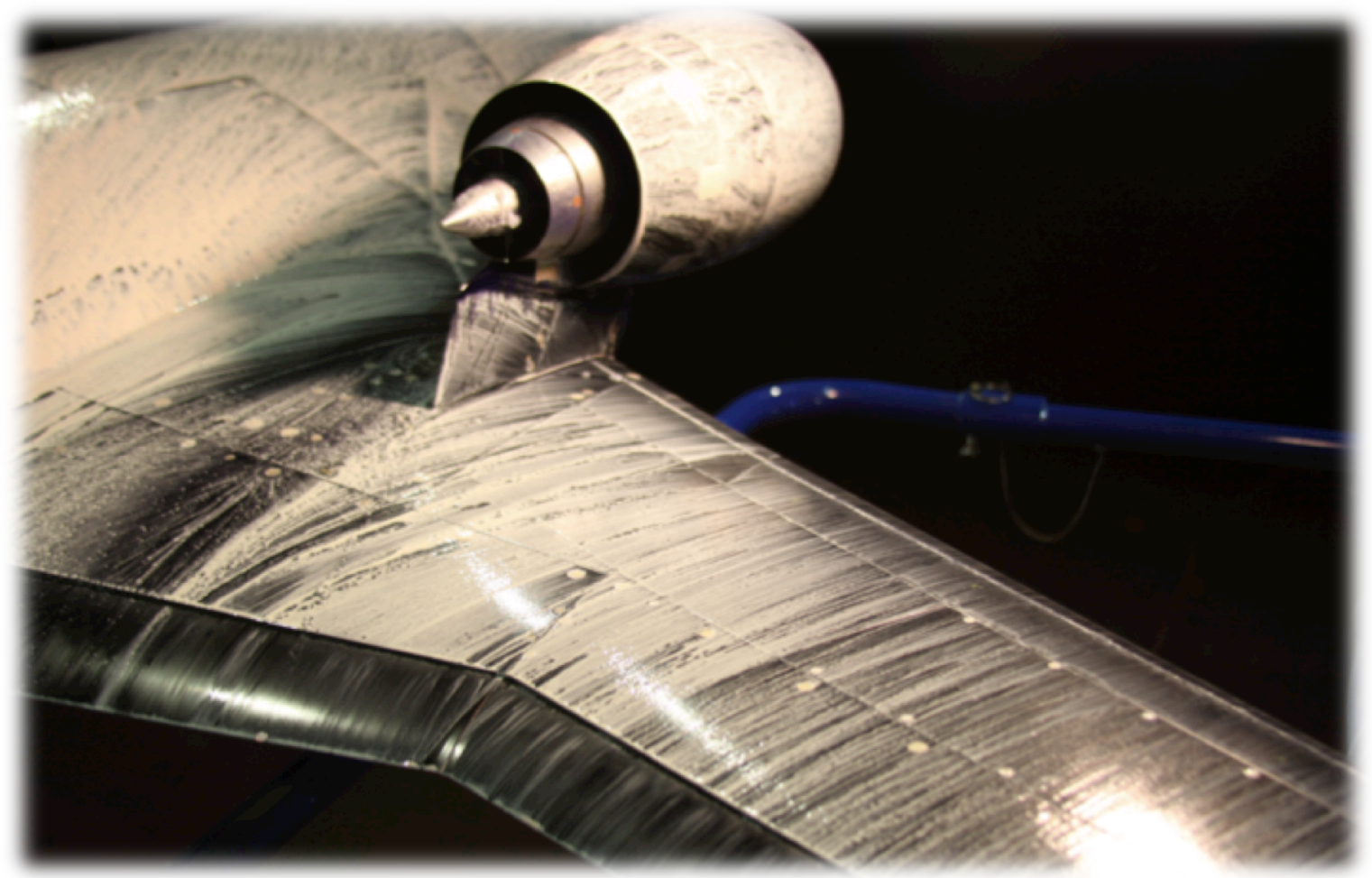

Figure 25. A photograph of AMELIA utilizing oil flow visualization to verify the quality of the flow exiting the circulation control wing plenums at $40 \mathrm{kts}$ and a momentum coefficient of 0.8 .

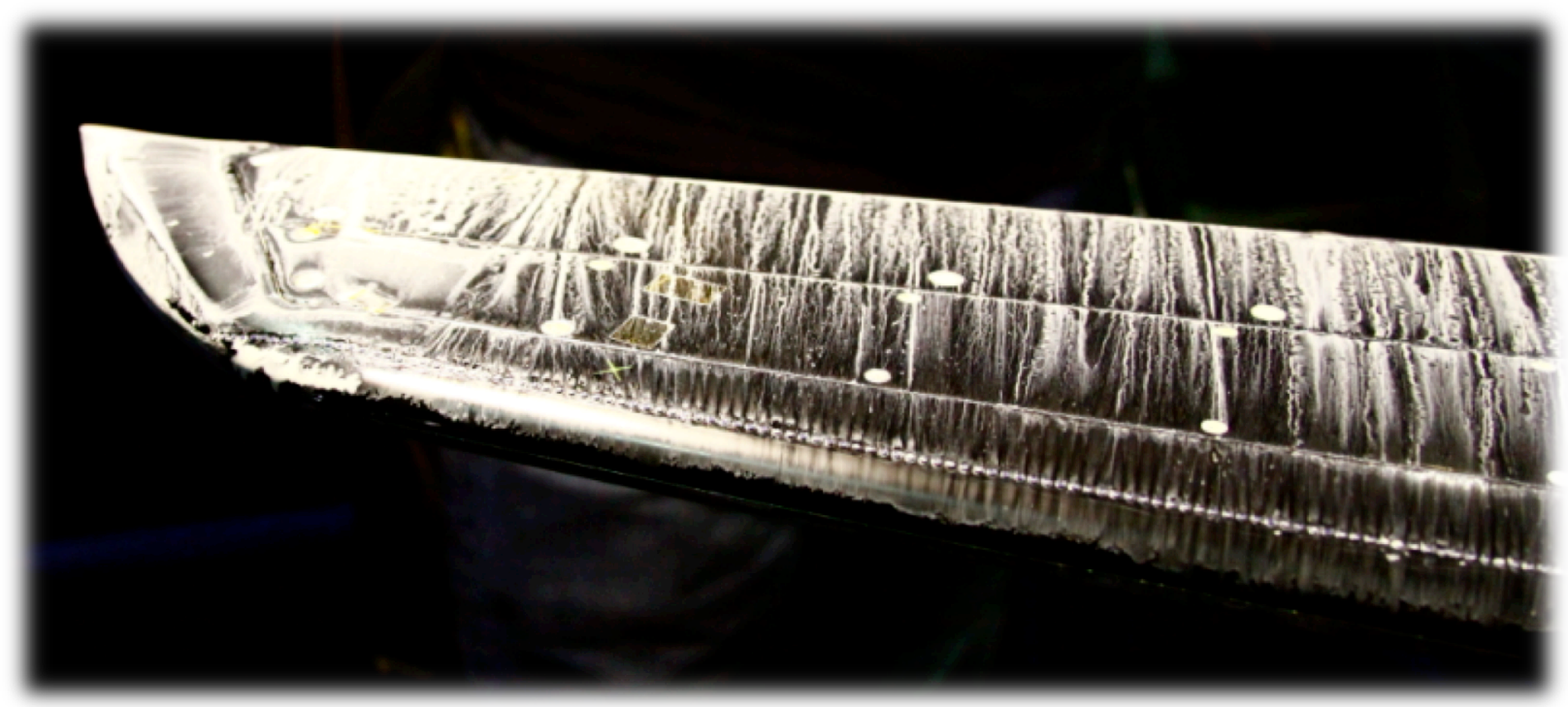

Figure 26. A photograph of the AMELIA wing tip with the oil flow visualization technique illustrating the wing tip flow physics does not follow the inboard section of the wing where the momentum flow has attached the flow exiting the plenums. 


\section{Acknowledgements}

This work was funded as part of a NASA Research Announcement award under Contract \#NNL07AA55C with Craig Hange and Clif Horne as the technical monitors. The authors wish to thank all of the students who have participated in this work; their hard work and dedication have been invaluable to this research. Lastly, a special thank you to each and every person from the Fluid Mechanics Laboratory (FML) at Ames Research Center. The AMELIA project would have not have been such a success with out the guidance, input, and support from the FML staff.

\section{References}

${ }^{1}$ Collier F. Overview of NASA's environmentally responsible aviation (ERA) project. 2009 Fundamental Aeronautics Conference, Atlanta GA, oral presentation, 2009.

2 Marshall D. D., Lichtwardt J. A., Pham J., Blessing B., and Storm T. M., "Summary of the Aerodynamic Modeling Efforts for AMELIA," 51th AIAA Aerospace Sciences Meeting and Exhibit, AIAA, Grapevine TX, AIAA2013-0973, 2013.

${ }_{3}^{3}$ Jameson K. K., Marshall D. D., Golden R., Paciano E. N., Englar R. J., Gaeta R. J., Paterson J., and Mason D., "Part 1: The Wind tunnel Model Design and Fabrication of Cal Poly's AMELIA 10 foot Span Hybrid Wing-Body Low Noise CESTOL Aircraft.," 49th AIAA Aerospace Sciences Meeting and Exhibit, AIAA, Orlando FL, AIAA2011-1306, 2011.

${ }^{4}$ Lichtwardt, J. A., Paciano, E. N., Jameson, K. K., and Marshall, D. D., "STOL Performance of Cal Poly's AMELIA," 51th AIAA Aerospace Sciences Meeting and Exhibit, AIAA, Grapevine TX, AIAA-2013-0976, 2013.

${ }^{5}$ Golden R and Marshall D D. Design and performance of circulation control flap systems," 48th AIAA Aerospace Sciences Meeting and Exhibit, AIAA, Orlando FL, AIAA 2010-1053, 2010.

${ }^{6}$ Englar R J, Gaeta R J, Lee W J and Leone V. Development of pneumatic over-the-wing powered-lift technology; part I: aerodynamic propulsive. 27th AIAA Applied Aerodynamics Conference, AIAA, San Antonio TX, AIAA-2009-3942, 2009.

${ }^{7}$ Paciano, E. N., Lichtwardt, J. A., Jameson, K. K., Marshall, D. D., and Fong R., "Flow Uniformity Calibration of AMELIA's Circulation Control Wings," 51th AIAA Aerospace Sciences Meeting and Exhibit, AIAA, Grapevine TX, AIAA-2013-0975, 2013.

${ }^{8}$ Ehrnamm, R, Paciano, E. N., Lichtwardt, J. A., and Jameson, K. K., "Global Skin Friction Measurements on a Circulation Control Airliner in the NFAC," AIAA Aerospace Sciences Meeting and Exhibit, AIAA, Grapevine TX, AIAA-2013-0977, 2013.

${ }^{9}$ Jones G S. Pneumatic Flap Performance for a two-dimensional circulation control airfoil. Applications of Circulation Control Technology, edited by R. D. Joslin and G. S. Jones, Vol. 214 of Progress in Astronautics and Aeronautics, chap. 7, American Institute of Aeronautics and Astronautics, Inc., pp. 191-244, 2006.

${ }^{10}$ Englar R J. Experimental Development and evaluation of pneumatic powered-lift super-STOL aircraft. Applications of Circulation Control Technology, edited by R. D. Joslin and G. S. Jones, Vol. 214 of Progress in Astronautics and Aeronautics, chap. 7, American Institute of Aeronautics and Astronautics, Inc., pp. 191-244, 2006.

${ }^{11}$ Collier F, Zavala E, and Huff D. Fundamental aeronautics program, subsonic fixed wing reference guide. NASA.

${ }^{12}$ Marshall, D., and Jameson, K., "Overview of Recent Circulation Control Modeling Activities at Cal Poly", AIAA-2010-348, AIAA $48^{\text {th }}$ Aerospace Sciences Meeting and Exhibit, Orlando, Fla.

${ }^{13}$ Lane K A and Marshall D D. A surface parameterization method for airfoil optimization and high lift 2D geometries utilizing the CST methodology. 47th AIAA Aerospace Sciences Meeting and Exhibit, AIAA, Orlando FL, AIAA-2009-1461, 2009.

${ }^{14}$ Lane K A and Marshall D D. Inverse airfoil design utilizing CST parameterization. 48th AIAA Aerospace Sciences Meeting and Exhibit, AIAA, Orlando FL, AIAA-2010-1228, 2010.

${ }^{15}$ Golden R and Marshall D D. Design and performance of circulation control flap systems," 48th AIAA Aerospace Sciences Meeting and Exhibit, AIAA, Orlando FL, AIAA 2010-1053, 2010. 
${ }^{16}$ Englar R J, Gaeta R J, Lee W J and Leone V. Development of pneumatic over-the-wing powered-lift technology; part I: aerodynamic propulsive. 27th AIAA Applied Aerodynamics Conference, AIAA, San Antonio TX, AIAA-2009-3942, 2009.

${ }^{24}$ Gaeta R J, Englar R J and Avera M. Development of pneumatic over-the-wing powered lift technology Part II: aeroacoustics. 27th AIAA Applied Aerodynamics Conference, AIAA, San Antonio TX, AIAA-2009-3941, 2009. 